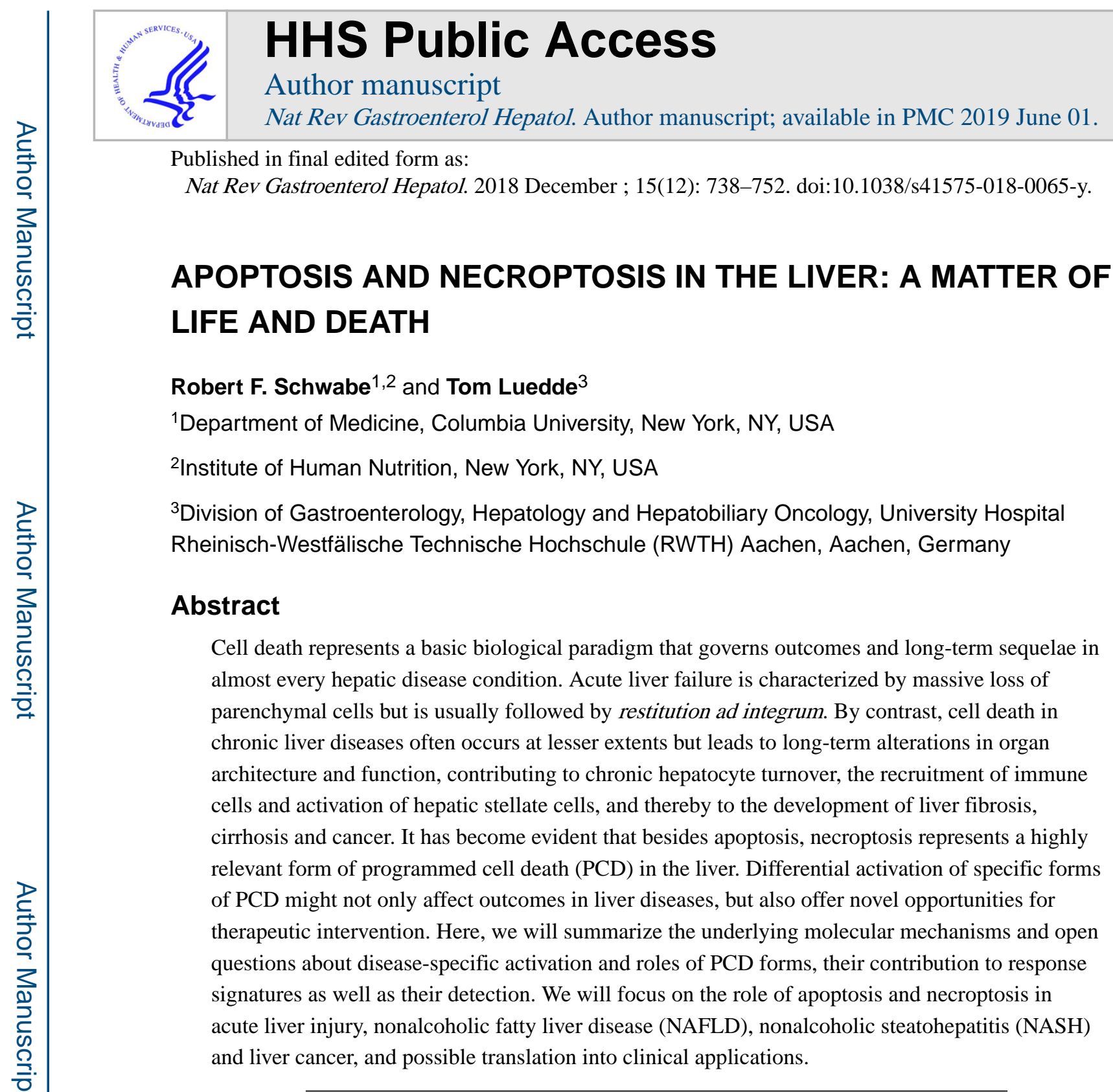

\title{
INTRODUCTION
}

In the normal liver, almost all cells are in a resting $\mathrm{G} 0$ phase [with little turnover and virtually no cell death ${ }^{1,2}$. This state becomes perturbed in chronic liver disease, in which viral, toxic, metabolic or autoimmune injuries induce hepatocellular death, followed by inflammation and compensatory hepatocyte proliferation ${ }^{3}$. Although these responses ensure efficient regeneration in the setting of acute hepatocellular injury, chronic hepatocyte death and the associated inflammation have been closely linked to the development of fibrosis, cirrhosis and hepatocellular carcinoma (HCC) ${ }^{3}$. Accordingly, HCC almost exclusively develops in patients with chronic liver disease (CLD), whereas cancer in many other organs such as the colon, pancreas, kidney and brain often develops spontaneously in the absence of chronic injury or disease ${ }^{4}$. In contrast to most other organs, the liver possesses a profound ability to regenerate - full liver mass following two thirds partial hepatectomy is restored 
within 7-10 days, reflecting the liver's essential role in many vital processes ${ }^{1}$. However, there are only minor changes in the liver's synthetic function in the early stages of CLD, as evidenced by normal levels of serum albumin, clotting factors and cholesterol and bile acid metabolism and lack of clinical symptoms ${ }^{5}$. On the one hand, this reflects the functional reserve of the liver; on the other, it seems that the liver's prototypical response towards cell death is geared towards the threat of acute liver failure and that there is no or only insufficient fine-tuning of cell death responses in CLD. Accordingly, the wound healing responses in CLD have been characterized as maladaptive ${ }^{3}$, increasing the risk for disease progression and cancer in the long run.

Whereas evidence from clinical studies and animal models has clearly established the strong association of hepatocyte death with key complications of CLD - that is, fibrosis, cirrhosis and HCC development - we are only beginning to understand mechanisms through which cell death in the liver contributes to these complications. In the past decade, it has become apparent that cell death comes in many flavours, and that different modes of cell death can be activated in disease, triggering distinct responses and biological outcomes ${ }^{6-10}$. As such, physiological cell death during development and organ turn-over is ideally non-reactive in terms of compensatory regeneration and immune cell activation ${ }^{11}$; toxic and/or massive cell death should trigger regenerative responses ${ }^{10,12}$; and cell death induced by pathogens ideally eliminates pathogens and elicits immune responses ${ }^{13}$. Besides necrosis and apoptosis as well-established forms of cell death, several new modes of cell death have been discovered and characterized in the past decade, including necroptosis, pyroptosis and ferroptosis $8,9,14$. Hence, it is conceivable that specific modes of cell death are tailored for specific settings. Importantly, different modes of cell death might endow us with new opportunities to therapeutically modify the course of CLD, either by directly interfering with mediators that regulate each form of cell death; or with mediators that promote responses to specific types of cell death. In the present Review, we will focus on apoptosis and necroptosis, the current knowledge on their interplay and connections to cell death responses as well as their roles in murine models of liver disease and in patients. Given the fast expansion of knowledge on each form of cell death, we focus here on the distinct functions of apoptosis and necroptosis in liver disease in order to allow a sufficiently deep insight within the frame of this paper. Pyroptosis, ferroptosis and autophagic cell death represent alternative forms of programmed cell death that might prove equally important in liver disease as apoptosis or necroptosis. However, despite promising data from studies published in the past few years ${ }^{15-17}$, the overall experimental evidence for their potential function in liver injury and carcinogenesis seems to be less advanced, so we refer the reader to excellent reviews on these pathways $8,9,18-20$.

\section{PRINCIPLES OF APOPTOSIS AND NECROPTOSIS}

Cell death can occur in distinct pathophysiological contexts. On one hand, in the setting of massive hypoxic or toxic injury, cells can reach a state of cellular stress and energy depletion in which they lose their ability to maintain basic homeostatic functions, resulting in necrosis, a passive and uncontrolled autolytic loss of cellular integrity ${ }^{21}$. Morphologically, cells undergoing necrosis typically show a swelling and disruption of cell membranes and organelles without the picture of pyknosis (a reduction of cellular and nuclear volume) seen 
upon chromatin condensation in apoptosis ${ }^{22}$. In the liver, necrosis is observed in multiple disease contexts and experimental models, such as ischemia-reperfusion injury or acute liver injury due to $\mathrm{CCl}_{4}$ treatment or acetaminophen (also known as paracetamol) intoxication ${ }^{23}$. Moreover, necrosis is believed to trigger a massive inflammatory response that can cause substantial collateral damage to neighbouring cells ${ }^{24}$. In contrast to passive necrosis that results from detrimental injury or stress, cell death can also be executed in an ordered, regulated fashion via a specific suicide program, termed apoptosis, which exerts only minimal effects on surrounding cells and thereby does not disrupt tissue homeostasis or organ development. For years, the term apoptosis was used synonymously with the term programmed cell death, until it became evident that additional forms of programmed cell death exist. Morphologically, apoptosis is characterized by cellular shrinkage, a dense cytoplasm with tightly packed organelles and pyknosis caused by the characteristic condensation and fragmentation of chromatin ${ }^{22}$. The biochemical execution of apoptosis is mediated by the activation of initiator and executioner caspases, which kill cells through the cleavage of proteins and subsequent activation of nucleases that cleave DNA into short, regularly sized fragments 25 .

\subsection{Regulation of apoptosis and necroptosis}

As the execution of apoptosis is considered an irreversible process, whereby caspase activation commits a cell to death, the activation of the apoptosis machinery is a tightly regulated process. Caspase activation can be either mediated through the 'intrinsic', mitochondrial dependent pathway ${ }^{25}$, or through the extrinsic, death receptor-dependent pathway that is triggered, for example, through TNF signalling or activation of Fas by Fas ligand ${ }^{26}$. Whereas Fas activation triggers death in many cell types, TNF simultaneously activates pro-apoptotic and anti-apoptotic signals and cells only die if anti-apoptotic signals, mostly mediated by NF- $\kappa$ B activation, are suppressed ${ }^{27}$ (Figure 1). Binding of TNF to its receptor TNFR1 induces the transient formation of a primary membrane-bound signaling complex, known as TNFR1-complex I, which mediates the expression of pro-survival genes like c-FLIP, bcl-xL or XIAP ${ }^{28}$. As part of complex I, the adaptor proteins TRADD and the kinase RIPK1 are recruited to the receptor, serving as platforms for the recruitment of various other proteins including TRAF2 and members of the Inhibitor of Apoptosis Protein (IAP) family, cIAP1 and cIAP2. Through complex ubiquitination events involving the generation of K63-linked, K11-linked, K48-linked and linear ubiquitin chains, the TAB2/3TAB1-TAK1 complex and the I- $\kappa B-K i n a s e(I K K-)$ complex (consisting of the kinases IKKa, IKK $\beta$ and the regulatory subunit NEMO) are recruited to complex 1 (Figure 1). The kinase TAK1 in many cell types activates MAP kinases like JNK, ERK and p38, but experiments in Tak1-deficient liver cells showed that their activation in hepatocytes can be mediated independently of TAK $1{ }^{29,30}$. However, TAK1 is absolutely essential to phosphorylate IKK $\beta^{29}$, which drives ubiquitination and proteasomal degradation of the inhibitory protein $\mathrm{I} \kappa \mathrm{Ba}$, thereby allowing NF- $\mathrm{kB}$ dimers consisting of p50 and p65 (RelA) to translocate to the nucleus and drive the transcription of NF- $\mathrm{kB}$-dependent genes like cFLIP, cIAPs or A20.

Defective activation of NF- $\mathrm{kB}$ (for instance through genetic deletion of Nemo ${ }^{31,32}$ or p65/ RelA) ${ }^{33}$ switches cellular TNF responses from survival towards cell death by the formation 
of a caspase 8-activating complex called complex II (Figure 1), and a cascade of downstream signals that promote or amplify cell death signals such as JNK, BID, SMAC and cytochrome C (reviewed in 27,34,35 - see Figure 2). Complex IIa forms upon dissociation of TRADD from complex I and association with FADD, thereby forming a platform for the activation of Caspase-8, a process that is counteracted by the NF- $\kappa B$ target gene c-FLIP ${ }^{28}$. Although complex IIa depends on TRADD, an alternative death complex called complex IIb is highly dependent on the kinase activity of RIPK1 and mediates apoptosis independently of NF- $\kappa \mathrm{B}$ target genes. RIPK1-dependent apoptosis in hepatocytes can be specifically activated through combined deletion of IKKa and IKK $\beta$, because these kinases directly phosphorylate RIPK1 at several serine residues (for example S330 and S331) ${ }^{36}$, thereby preventing the auto-activation of RIPK1-dependent cell death in an NF- $\kappa \mathrm{B}$-independent fashion. Finally, beyond its pro-apoptotic role, RIPK1 has a kinase-independent antiapoptotic function in hepatocytes facilitated by the prevention of ubiquitination and degradation of the survival molecule TRAF2 ${ }^{37,38}$.

For many years, the term apoptosis was used synonymously with programmed cell death, whereas necrosis was considered a purely accidental, non-regulated form of cell death. However, it has long been know that TNF can induce both apoptosis and cell death with features of necrosis ${ }^{39}$. In 1998, the group of Peter Vandenabeele showed that inhibition of Caspases triggered a controlled form of necrosis in fibrosarcoma cells ${ }^{40}$. This new form of necrosis - similar to complex IIb-dependent apoptosis - was subsequently shown to depend on RIPK1 and was named necroptosis ${ }^{41,42}$. Finally, in 2009 and 2010, several groups showed that the kinase RIPK3 (also termed RIP3) and the pseudokinase MLKL are additional key mediators of necroptosis ${ }^{43-46}$. In this pathway, activation of RIPK1 and parallel inhibition of caspase 8 promote a shift from RIPK1-induced apoptosis (complex IIb) towards necroptosis, mediated by the necrosome, a complex containing RIPK1, RIPK3 and MLKL (Figure 1). After phosphorylation of MLKL by RIPK3, p-MLKL undergoes a conformational change and oligomerizes, after which it binds to lipids in the plasma membrane. This binding is sufficient to perforate membrane structures and execute cell lysis 47.

\section{FUNCTIONS OF APOPTOSIS AND NECROPTOSIS}

Cell death occurs in many settings, including development, homeostasis, chemical, physical or hypoxic injury, and cancer. The existence of multiple forms of cell death not only provides the ability to kill cells by the most appropriate method for a specific context but also provides back-up mechanisms in settings in which specific types of cell death fail or are actively evaded. Caspase 8 is not only an important part in the execution of apoptosis but also represents a central switch that directs cell death towards specific types of cell death: activation of Caspase- 8 promotes apoptosis whereas suppression of Caspase- 8 activity shifts the balance towards necroptosis ${ }^{7}$. Vice versa, it has been suggested that activity of RIPK3 determines the execution of apoptosis, with catalytically inactive RIPK3 promoting apoptosis ${ }^{48}$. Thus, apoptosis and necroptosis seem to regulate each other reciprocally. As a number of pathogens or tumour cells have the ability to suppress Caspase he ability to suppress Caspase-than NFcroptosis?and MLKL? Canngctivated MLKL and prevents n activity, necroptotic cell death has been proposed to serve as backup system that enables the 
killing of infected or malignant cells. This hypothesis is consistent with a central role of these two forms of programmed cell death as defense mechanisms against infections ${ }^{13}$. Although the presence of a backup programmed cell death mechanism might be advantageous in specific settings such as viral infection or cancer, the suppression of necroptosis by Caspase- 8 activity is also an important feature of the healthy state.

Accordingly, loss of Caspase- 8 during development is detrimental and leads to embryonic lethality between embryonic days 10.5 and 11.5. This has been ascribed to the lack of necroptosis suppression rather than the inability to kill cells via apoptosis ${ }^{49}$. As many stimuli that trigger apoptosis, such as TNF, can also engage necroptosis and as these two types of cell death regulate each other, further research is needed to define their relative roles in disease settings besides viral infection. The non-inflammatory nature of apoptosis in most settings probably results from the lack of cellular leakage and the rapid clearance of apoptotic cells or bodies by phagocytic cells via specific 'find me' and 'eat me' signals (discussed later) ${ }^{50-52}$. By contrast, necroptotic death is mediated by the rupture of the plasma membrane and release of cellular contents, which presumably triggers substantial inflammation ${ }^{53}$. Thus, one of the biggest differences between apoptosis and necroptosis is the ensuing response to cell death, which often dictates the long-term outcome in patients with liver disease. Despite this clear distinction between inflammatory necroptosis and noninflammatory apoptosis, apoptotic cells can trigger inflammation in specific settings, possibly owing to secondary necrosis, in particular when apoptotic cells escape efferocytosis (the process by which dead cells are removed by phagocytic cells) ${ }^{50}$. Evasion of efferocytosis might promote inflammation not only through secondary necrosis but also through lacking anti-inflammatory signals in phagocytic cells triggered by efferocytosis ${ }^{54}$. Likewise, decreasing ATP levels in hepatocytes might make it impossible to maintain energy-consuming apoptosis and result in conversion to secondary necrosis ${ }^{23,55}$. However, this effect is more likely to be seen in vitro, where apoptotic cells are not eliminated by efferocytosis when cultured and killed in the absence of phagocytic cells. Substantial secondary necrosis in vivo is more likely to occur when efferocytosis is either inhibited or overwhelmed (e.g. in livers of mice with conditional deletion of $T a k 1^{30}$ ).

\section{RESPONSES TO APOPTOSIS AND NECROPTOSIS}

Whereas the recognition of non-self antigens is the principal driver of the adaptive immune system, conserved molecular patterns activate innate immune responses via specific pattern recognition receptors (PRRs). The 'danger theory' proposes that the innate immune system recognizes not only foreign molecular patterns but all forms of danger, in particular cell damage and cell death ${ }^{56}$. In this theory, apoptotic cell death results in a lower degree of inflammation than necroptotic cell death, mostly due to the rapid clearance of apoptotic cells via specific 'find me' and 'eat me' signals 51,52 but possibly also by Caspase-8-mediated suppression of the NLRP3 inflammasome ${ }^{57}$. Moreover, apoptotic cells might also locally suppress inflammation by release 'keep out' signals such as lactoferrin or anti-inflammatory mediators such as TGF- $\beta$ or PD-L1. By contrast, cell rupture after necroptosis leads to the release of inflammatory damage-associated molecular patterns (DAMPs), which can activate the innate immune system and neighboring cells via PRRs ${ }^{53}$. Moreover, RIPK3 activation has also been implicated in the activation of the NLRP3 inflammasome ${ }^{57-59}$. However, in 
the liver the distinction between non-reactive apoptosis and highly reactive necroptosis and necrosis does not seem to reflect clinical findings, because apoptosis is clearly associated with disease development and often leads to cellular leakage and inflammation. This finding could be due to a number of factors: an insufficient ability of phagocytic cells to clear apoptotic cells in the setting of massive injury, which might lead to secondary necrosis and release of DAMPs ${ }^{50}$; co-existence of apoptosis with other forms of cell death; or yet unknown features of hepatocyte apoptosis, which might trigger inflammatory signals in phagocytic or other cell types in specific settings ${ }^{3}$, possibly to enable hepatocyte regeneration and restoration of liver function following loss of hepatocytes via apoptosis. In chronic liver disease that spans over years or decades, cell death triggers chronic inflammation, regeneration and a progressive buildup of extracellular matrix (ECM) ${ }^{3}$. These three responses to hepatocyte death are thought to drive disease progression and the development of HCC in CLD (Figure 3).

\subsection{Fibroinflammation}

With the activation of fibrogenic cells being concerted by proinflammatory cells and mediators ${ }^{60}$, it seems that cell death largely promotes fibrosis through inflammation rather than directly triggering it (Figure 3). However, apoptotic bodies ${ }^{61,62}$ and possibly also DAMPs (R.F.S., unpublished data) might directly activate fibrogenic cells, thus bypassing inflammatory cells and mediators. Qualitative and quantitative changes in ECM alter epithelial cell behaviour and might activate tumour-promoting pathways, in part through increased stiffness and via mechanosensitive signalling pathways such as YAP ${ }^{63}$. Chronic inflammation contributes not only to fibrosis but also to epithelial proliferation and survival as well as increased oxidative stress, all of which might promote the development of HCC 64 . The relative potency of apoptosis versus necroptosis to trigger fibrogenesis remains unknown. Although the most popular animal models for liver fibrosis (such as $\mathrm{CCl}_{4}$ and thioacetamide models) are triggered by necrosis, there is a strong correlation between markers for apoptosis and development of fibrosis in patients ${ }^{3}$.

\subsection{Regeneration}

The non-hierarchical organization of the liver, in which virtually any hepatocyte can serve as a facultative progenitor or stem cell, endows the liver with a rapid and often life-saving ability to regenerate, requiring only about one to two rounds of hepatocyte replication to replenish an entire liver after hepatocyte death or surgical loss of liver mass ${ }^{65}$. However, hepatocyte duplication, the predominant form of hepatocyte repopulation in most settings 66-68, might pose a higher risk for the accumulation of cancer-promoting mutations than repopulation from a hierarchical organization: Stem cells in a hierarchical system are typically low-proliferating, capable of undergoing asymmetric cell divisions and have low levels of DNA damage-induced metabolites ${ }^{69,70}$; these properties mean that cancerpromoting mutations are likely to occur at reduced frequencies. Moreover, mutations occurring in differentiated cells are less likely to lead to cancer, as these cells are usually eliminated by normal turn-over. Accordingly, chronic hepatocyte regeneration in CLD triggers replication-induced DNA damage ${ }^{71}$. Currently, it is not known whether apoptosis and necroptosis activate different regenerative responses. Specific modes of death or low levels of DAMPs might predominantly trigger regeneration from hepatocytes and that other 
modes of cell death or high levels of DAMPs trigger regeneration from liver progenitor cells. The fact that lost hepatocytes need to be replaced regardless of the type of cell death suggests that even non-reactive forms of cell death such as apoptosis must trigger some regeneration responses, unless other hepatostat-sensing mechanisms detect reduced liver independently of cell death detection.

\subsection{Immune responses}

Cell death can also be immunogenic. This aspect is best demonstrated in the context of cancer chemotherapy and radiotherapy, in which the combined release of tumour-associated antigens (TAA) and damage-associated molecular patterns (DAMPs) from dying cells enhances anti-tumour responses ${ }^{72-74}$ suggesting that the effects of cytostatic and cytotoxic therapies are at least in part mediated through immune mechanisms (Figure 3). In contrast to immunogenic cell death induced by cytostatic therapies, cell death in non-transformed and tumour ce_lls is often tolerogenic, probably owing to the lack of TAA release and high levels of DAMPs ${ }^{73}$. It can be speculated that hepatocyte death promotes immune responses in advanced CLD and contributes to the elimination of malignant cells. Although it has been suggested that necroptotic cell death is more reactive and immunogenic than apoptotic cell death, a number of studies have revealed apoptosis as an immunogenic form of cell death in the context of chemotherapy and radiotherapy ${ }^{72-74}$.

\subsection{Sensing and responding to cell death}

According to the danger theory, activation of the innate immune system can also be achieved by danger signals from cells undergoing non-physiological cell death. Accordingly, many danger-sensing PRRs have a wide ligand space to enable the detection of both pathogenassociated molecular patterns (PAMPs) such as LPS and DAMPs ${ }^{75}$. Hence, PRRs such as toll-like receptors (TLRs) or formyl-peptide receptors (FPRs) can detect danger regardless of whether it is triggered by infection or tissue injury. Consistent with the definition of apoptosis as non-reactive form and necrosis/necroptosis as reactive and inflammatory form of cell death, it has also been long believed that disruption of cellular integrity in necrosis and necroptosis results in DAMP release whereas apoptotic cells release virtually no DAMPs ${ }^{24,53}$. However, DAMPs might also be released following apoptosis, and that this effect could be one of the reasons why apoptosis is not always non-reactive. For instance, DAMPs such as high mobility group box 1 (HMGB1) are released from hepatocytes following stimulation with Fas-agonistic antibody Jo2 in vitro ${ }^{76}$ or in vivo (RFS, unpublished data), or in the context of chemotherapy or radiotherapy, in which cell death is mostly apoptotic 77 .

3.4.1. HMGB1.-This protein is a prototypical DAMP that is released from dying or stressed hepatocytes ${ }^{78,79}$. HMGB1 is thought to be only released from cells undergoing necrosis or necroptosis, whereas it is firmly bound to DNA in apoptosis because of generalized underacetylation of histones ${ }^{80}$. However, high levels of HMGB1 are released from hepatocytes following stimulation with Fas-agonistic antibody Jo2 in vitro ${ }^{76}$ or in vivo (RFS, unpublished data), suggesting that HMGB1 is released in the injured liver regardless of cell death mode. However, the consequences of HMGB1-mediated cell death seem to differ between apoptotic and necrotic hepatocyte death. Despite HMGB1 release, TNF- 
induced and Fas-induced liver disease did not differ between Hmgb1-deleted and control mice in the extent of injury, inflammation or survival ${ }^{79}$. By contrast, HMGB1 release had a major effect on sterile inflammation following necrotic injury induced by acetaminophen or hepatic ischemia-reperfusion ${ }^{79}$. Mice with hepatocyte-specific deletion of HMGB1 had not only decreased neutrophil recruitment but also decreased injury at late time points, suggesting that HMGB1-recruited neutrophils exacerbate injury ${ }^{79}$. In chronic liver injury, HMGB1 effects on sterile inflammation are much less pronounced, probably due to the dominant role of chemokines in neutrophil recruitment (RFS, unpublished data). Although some studies have suggested a role for HMGB1 in promoting liver fibrosis ${ }^{81}$, others have shown HMGB1 has no role in fibrogenesis in a wide range of mouse models and no effect on hepatocyte regeneration following partial hepatectomy or $\mathrm{CCl}_{4}$ insult ${ }^{78,82}$. However, HMGB1 has an important function in the progenitor response, with strong decreases of hepatocyte progenitor marker expression across five different models ${ }^{78,82}$. HMGB1 was involved not only in the hepatic progenitor response but also the dedifferentiation of HCC, with less and more differentiated HCC developing in mice lacking HMGB ${ }^{78}$. Effects of HMGB1 inhibition on HCC were only observed in HCC mouse models with chronic injury and absent in the purely genotoxic diehtylnitrosamine HCC model. Moreover, promoting effects of HMGB1 on progenitor responses were also apparent when HMGB1 was selectively deleted in hepatocytes. Together, these data show that HMGB1, acting as a DAMP and not through a cell-autonomous nuclear or intracellular function, contributes to the development of acute and chronic liver disease, with most effects in the liver requiring the presence of its receptor RAGE ${ }^{78,79,82}$.

3.4.2. ATP.-Injured hepatocytes release ATP, which triggers neutrophil recruitment to the liver but is not required for neutrophil chemotaxis toward of injury ${ }^{83}$. ATP stimulates neutrophil recruitment via its receptor P2X7, and subsequent activation of the Nlrp3 inflammasome and IL-1 production ${ }^{83}$. Accordingly, increased degradation of ATP via apyrase treatment inhibits neutrophil recruitment whereas genetic deficiency of CD39, an ATP-degrading ectonucleotidase, increases hepatic inflammation and injury in a sepsis model ${ }^{84}$. The role of ATP and its receptor P2X7 in acetaminophen-induced liver injury remains controversial. In one study, P2X7-/- mice or apyrase-treated mice had decreased liver necrosis whereas liver injury and mortality were increased in mice lacking CD39 85 . However, in another study P2X7-deficient or apyrase-treated mice had no difference in inflammation and injury following acetaminophen treatment ${ }^{86}$.

3.4.3. Formyl peptides.-Derived from either bacterial and mitochondrial proteins, formyl peptides are recognized by receptors of the formyl peptide receptor (FPR) family. FPRs are G protein-coupled chemoattractant receptors with key roles in host defense and inflammation. For example, following heat-induced liver injury, formyl peptide signals from necrotic cells guide neutrophils through non-perfused sinusoids into the injury area ${ }^{83}$. Following acetaminophen overdose in a mouse model, blockade of FPR1 moderately reduced hepatic neutrophil recruitment and liver injury ${ }^{87}$. As one of the main functions of FPRs is the recognition of bacterial ligands, it is not surprising that FPR-deficient mice show reduced neutrophil recruitment into the liver after bacterial infections such as Listeria monocytogenes ${ }^{88}$. 
3.4.4. DNA.-The release of DNA from apoptotic hepatocytes as well as CpG DNA induce the activation of hepatic stellate cells, as determined by measurement of Collal and Tgfb1 mRNA, via binding to TLR9 ${ }^{89}$. Accordingly, TLR9-deficient mice show reduced liver fibrosis following treatment with $\mathrm{CCl}_{4}{ }^{89}$.

3.4.5. IL-33.-A member of the IL-1 family, IL-33 is predominantly released from necrotic cells. In contast, in apoptotic cells IL-33 is cleaved by proapoptotic caspases resulting in reduced bioactivity and reduced stability ${ }^{90,91}$. Thus IL-33 is a classical DAMP that is tightly linked to necrosis or necroptosis, and its levels are reduced after knockout of Ripk3 or Mlkl but not Caspase $8{ }^{92}$. IL-33 mediates not only skin and lung fibrosis ${ }^{93,94}$ but also liver fibrosis induced by $\mathrm{CCl}_{4}$ administration, bile duct ligation and Schistosoma mansonii infection. ${ }^{94-96}$. In the liver, IL-33 does not mediate fibrosis through direct effects on hepatic stellate cells but rather through IL-33-induced increases in IL-13 production in type 2 innate lymphoid cells and subsequent hepatic stellate cell activation ${ }^{95}$. However, the effects of IL-33 in the liver seem to be context-dependent as IL-33 deficiency did not ameliorate high-fat diet-induced liver fibrosis in a mouse model ${ }^{97}$.

3.4.6. Monosodium urate.-Also known as uric acid, monosodium urate is a DAMP released in the setting of cellular death ${ }^{98}$. Crystalline monosodium urate, but not soluble uric acid, is a potent inducer of inflammation, mediated by activation of the NLRP3 inflammasome ${ }^{99}$. Monosodium urate induces the activation of mouse and human hepatic stellate cells in vitro, as demonstrated by increased expression of Col1a1 and Tgfb1 ${ }^{100}$. Moreover, mice lacking the NLRP3 inflammasome had reduced liver fibrosis following $\mathrm{CCl}_{4}$ or thioacetamide treatment ${ }^{100}$.

\section{DETECTION OF APOPTOSIS AND NECROPTOSIS}

Cellular stress and cell death triggered by various pathogenic factors is the basis of most if not all acute and chronic liver diseases. Hence, substantial efforts have been made to evaluate which form of cell death underlies specific liver diseases in order to develop not only new biomarkers but also specific therapeutic strategies. At present, apoptosis is the best characterized form of cell death in liver disease. Apoptosis shows clear morphological features usually affecting single cells, whereas the classic perception of necrosis normally referred to clusters of parenchymal cells with the morphological features described earlier. Moreover, the mechanisms driving apoptosis are well defined and feature unique aspects. Accordingly, specific histological tests can be applied to detect apoptotic cells in the liver. For instance, the cleavage of caspase- 3 , which is considered a final and irreversible step towards apoptotic cell death, can be detected by specific antibodies that work well in human and mouse liver tissue ${ }^{71}$. Importantly, the TUNEL (terminal deoxynucleotidyl transferase dUTP nick end labeling) test, which identifies cells with fragmented DNA, was believed to specifically detect apoptotic cells ${ }^{101}$, but this assumption had to be revised with the discovery of other forms of programmed cell death. Finally, mediators of apoptosis, such as cleavage products of caspases (for example CK18, detected by the monoclonal antibody M30) ${ }^{102}$ or soluble Fas and Fas ligand ${ }^{103}$ can be detected in the serum of patients and have been extensively studied for their possible role as prognostic biomarkers in liver disease ${ }^{104}$. 
The discovery of necroptosis put most of these paradigms into question, because this cell death form morphological and biochemical features with both apoptosis and necrosis. As such, necroptosis can be observed as a single cell event ${ }^{105}$, but can also affect clusters of parenchymal liver cells 30,36 . Moreover, necroptosis is mediated by molecules that can also facilitate apoptosis, such as RIPK1. At present, there is no specific test for the immunohistochemical detection of necroptosis (with a similar sensitivity and specificity as the available antibodies against cleaved caspase 3 for the detection of apoptosis), which partly explains the many controversies that still exist on the role of necroptosis in human liver disease. RIPK3 is normally expressed at somewhat low levels in human hepatocytes, but increased expression can be induced upon caspase 8 deletion as well as in distinct pathophysiological conditions such as $\mathrm{NASH}^{30,106}$. On the basis of experimental data from cell culture and mouse models, the activation of necroptotic cell death coincides with increased expression of RIPK $3{ }^{30}$. However, RIPK3 staining of human livers results in morphologically varying pictures 30,107 , raising substantial doubts about the specificity of commercially available antibodies for immunohistochemical analyses. By contrast, Western blots assessing RIPK3 expression seem to be more specific and reliable ${ }^{106}$, but do not allow a clear distinction between the activation of this pathway in parenchymal versus nonparenchymal cells.

For some time, the phosphorylation of MLKL was considered a specific and irreversible molecular event driving necroptosis ${ }^{46}$. Hence, an antibody detecting p-MLKL used to be considered a bona fide tool to specifically detect necroptotic cell death, and interestingly the use of such an antibody was first documented in human patients with drug-induced liver failure ${ }^{105}$. However, in our experience, the commercially available antibodies work very well in Western blots in experimental settings that trigger strong activation of MLKL (such as TNF stimulation of L929 osteosarcoma cells), whereas they are not sensitive enough to detect a subtle activation of MLKL in hepatocytes or livers with wild-type caspase 8 (for instance in mouse NASH models; data not shown). Moreover, several papers published in the past 2 years elegantly demonstrated that phosphorylation of MLKL does not necessarily lead to the execution of necroptotic cell death. As such, activated MLKL is part of a molecular process involving vesicle and exosome formation, in collaboration with the ESCRT-III machinery ${ }^{108}$. This promotion of p-MLKL cellular export represents a selfrestriction of activated MLKL and therefore a restriction of necroptosis ${ }^{109}$, illustrating that MLKL phosphorylation by itself is not sufficient to indicate cell death.

On the basis of these data, a combination of biochemical and morphological tests rather than one single method might be able to provide more solid evidence for the activation of necroptotic cell death in liver disease. As such, some authors combined stainings for cleaved caspase 3 with a TUNEL test - cells staining positive for both caspase 3 and TUNEL were considered apoptotic, whereas TUNEL positive cells that were negative for cleaved caspase 3 were considered necroptotic ${ }^{110}$. However, positive TUNEL staining and negative caspase 3 staining might also indicate other forms of non-apoptotic cell death, such as ferroptosis. In another study on the function of endothelial necroptosis in pulmonary spreading of tumour cells, the authors combined electron microscopic analyses for ultrastructural signs of necrosis with the detection of the uptake of Hoechst dye to identify necroptotic cells with leaky membranes in mouse lungs ${ }^{111}$. This approach could be applied to human liver 
disease, for instance by using precision-cut liver slices as a tool to model viable liver cells ex vivo $^{112}$. Until better detection methods are defined to enable the detection of specific cell death forms in vivo with a single test, the interpretation of whether necroptosis or apoptosis are relevant in specific liver disease aetiologies will rely on a combination of detection methods in human tissues as well as functional data gained in cell culture and murine disease models.

With the exception of a few cell lines that are exceptionally susceptible to necroptosis (such as L929 cells ${ }^{40}$ ), the activation of necroptosis in cell culture often requires an additional sensitization step. For instance, sensitization can be achieved by the addition of so-called SMAC mimetic agents (that induce degradation of cIAP proteins, thereby promoting cell death ${ }^{113}$ ) or the inhibition of apoptosis through chemical inhibitors (such as zVAD ${ }^{114}$ ), Caspase 8 competent wild-type hepatocytes express RIPK3 at low levels compared with many other cell types ${ }^{30}$. Therefore, primary hepatocytes require several interventional steps to execute necroptosis. By contrast, caspase 8 deletion from hepatocytes is sufficient to trigger hepatocyte necroptosis and inflammation in livers of mice in vivo ${ }^{30}$. This finding supports the notion that the threshold for activation of necroptosis is in general higher in isolated and cultured cells than in vivo, probably due to the effects of surrounding immune cells and the availability of potentially important co-factors and cytokines.

\section{APOPTOSIS AND NECROPTOSIS IN LIVER DISEASE}

\subsection{Acute liver injury}

Soon after the discovery of necroptosis, several studies assessed whether this pathway has a role in experimental models of acute liver injury (Figure 4). Intoxication with acetaminophen is the clinically most relevant cause for drug-induced liver injury (DILI) and can be reproduced in well-established mouse models ${ }^{115}$. Moreover, the histological appearance of acetaminophen-induced liver injury suggests the involvement of necrosis rather than apoptosis in this injury model ${ }^{116}$. However, several studies came to distinct and conflicting results on the role of necroptosis in acetaminophen-induced liver injury, probably because this pathway was modulated using different technical approaches, such as administration of the small molecule RIPK1 inhibitor Necrostatin-1 (Nec-1), anti-sense oligonucleotides against RIPK1 or RIPK3 mRNA, or mice with conditional or constitutive knockout of RIP kinases ${ }^{117-121}$. It has become clear that the earlier studies using Nec-1 in vivo need to be interpreted with caution, as Nec-1 is neither specific for RIPK1 nor stable in vivo $^{122}$. Moreover, two independent studies using Ripk3-deficient or Mlkl-deficient mice in the acetaminophen toxicity model did not confirm any statistically significant difference between wild-type and knockout mice ${ }^{116,118}$. Several studies suggested that acetaminophenrelated necrosis is not just executed randomly but influenced by several signaling pathways 123. In this line, it should be noted that acetaminophen overdosing causes massive drops in intracellular glutathione levels ${ }^{115}$, a key molecular mediator involved in the activation of ferroptosis ${ }^{124}$. However, the present data clearly suggest that acetaminophen-related liver injury is not substantially influenced by the necrosome as the key mediator of necroptotic cell death. This finding also raises doubts whether necroptosis - previously detected via pMLKL staining in patients with acute DILI ${ }^{105}$ - is a major contributor to human DILI. 
Similarly, the role of RIPK1 in acetaminophen-induced liver injury remains poorly understood. Whereas an antisense oligonucleotide approach against RIPK1 ameliorated acetaminophen-induced cell death ${ }^{118}$, this protective function was not confirmed in conditional, hepatocyte-specific RIPK1 knockout mice ${ }^{116}$.

The function of RIP kinases in acute liver injury was further investigated in the concanavalin A (ConA) model, which features aspects of an auto-immune-related injury mechanism dependent on T cells and TNF signalling ${ }^{125}$. Surprisingly, mice expressing a form of RIPK1 lacking kinase activity were protected in this model, whereas deletion of RIPK1 in hepatocytes aggravated ConA-induced liver injury ${ }^{126,127}$. Moreover, mice with ablation of RIPK3 were not protected in this model ${ }^{126}$. Together, these findings suggest that in this specific model RIP kinases have an apoptotic signalling role, with RIPK1 possessing a dual pro-apoptotic and anti-apoptotic function. In line with this hypothesis, it was previously shown in mice that the pro-apoptotic function of RIPK1 in Nemo-deficient hepatocytes depends on its kinase function ${ }^{32}$, whereas we identified a kinase-independent, anti-apoptotic scaffolding function of RIPK1 in hepatocytes that is mediated through the prevention of proteasomal degradation of the survival molecule TRAF2 ${ }^{37}$. Ischaemia-reperfusion injury is another form of acute organ injury and has been intensively studied in other organs such as brain ${ }^{128}$, kidney ${ }^{129}$ and heart ${ }^{130}$. In the liver, RIPK3 was upregulated following induction of ischaemia-reperfusion, but neither the deletion of Ripk 3 nor caspase 8 had any protective effect on the degree of liver injury in this model (T.L., unpublished data). This finding argues for non-controlled, passive necrosis as the major driver of hepatic ischaemiareperfusion injury, which seems logical in this pathophysiological setting. Taken together, several studies applying a variety of experimental interventions came to the conclusion that necroptosis was involved in the models most commonly used to study acute liver injury in mice (acetaminophen, ConA, ischaemia-reperfusion injury), but studies using genetic models could not confirm a substantial contribution of necroptosis for the acute injury phase in these experimental models. Given the limited evidence for the activation of necroptosis in livers of patients with acute liver injury, we presently do not see a rationale to test necroptosis inhibitors in clinical trials, for instance in the setting of DILI or autoimmune hepatitis.

\subsection{NASH and CLD}

Both alcoholic liver disease (ALD) and nonalcoholic fatty liver disease (NAFLD) are serious health problems with a global rise of incidence and importance ${ }^{131}$. Although patients with ALD consume excessive amounts of alcohol, NAFLD - the most common liver disease in the Western world ${ }^{132}$ - is typically defined by the presence of steatosis in $>5 \%$ of hepatocytes in patients with little or no alcohol consumption ${ }^{133}$. The term nonalcoholic steatohepatitis (NASH) defines a more severe form of NAFLD, characterized by hepatocyte steatosis, inflammation, hepatocyte cell death and often fibrosis ${ }^{134}$. Theories to explain the molecular and metabolic alterations driving the initiation and progression of NASH vary between a 'two hit hypothesis' 135 and a 'multiple hit hypothesis' ${ }^{136}$. In these concepts, the first hit constitutes rising hepatic lipid concentrations, which render hepatocytes sensitive to additional hits featuring oxidative stress and hepatocyte cell death that drives inflammation and fibrosis. 
In terms of hepatocyte cell death in NASH, most data point towards apoptosis as the key driver. Immunohistochemical tests assessing hepatocyte caspase 3 cleavage and TUNEL positivity were positive in both liver tissue from patients with $\mathrm{NASH}^{137}$ and in commonly used mouse models of NASH ${ }^{138}$. Moreover, non-invasive markers of apoptosis such as circulating CK18 levels are increased in patients with NASH and can predict the presence of the disease ${ }^{139}$. Finally, inhibition of apoptosis using the pan-caspase inhibitor VX-166 markedly reduced liver injury and liver fibrosis in $\mathrm{db} / \mathrm{db}$ mice fed a methionine-cholinedeficient (MCD) diet ${ }^{140}$. In line with these findings, the oral caspase inhibitor GS-9450 which inhibits caspases 1,8 and 9 - led to a reduction of alanine aminotransferase levels in patients with NASH in a clinical trial ${ }^{141}$. Other pan-caspase inhibitors such as emricasan are currently being tested in large randomized trials in NASH ${ }^{142}$.

However, studies have suggested that the role of apoptosis as the only cell-death mediator in NASH might potentially be overestimated and that necroptosis might be a fundamental element in the disease pathogenesis. Necrosis and necroinflammation are typical histological features of $\mathrm{NASH}^{134,143}$, suggesting the involvement of alternative cell death pathways. The initial publication of caspase 3 and caspase 7 cleavage in human NASH showed an immunohistochemical picture of almost $100 \%$ caspase 3 positive hepatocytes in patients with NASH, compared with no positivity in control cells ${ }^{137}$. However, even in the most severe form of acute liver failure, apoptotic hepatocytes represent a low percentage of all hepatocytes ${ }^{144}$, probably owing to rapid clearance. Thus, the specificity of some antibodies against cleaved caspase 3 might not be ideal for immunohistochemistry in steatotic livers. In our hands, antibodies detecting either activated caspases or RIPK3 expression work more specifically in Western blot than in immunohistochemical analyses. Using Western blot, we could not detect intrahepatic activation of apoptosis in mice fed with MCD diet, whereas RIPK3 was strongly upregulated in this model ${ }^{106}$. More importantly, deletion of caspase3 did not have a strong effect on circulating aminotransferase levels (a surrogate for hepatocytic cell death) in the MCD NASH mouse model ${ }^{138}$. Moreover, rather than being protective, ablation of caspase 8 strongly aggravated liver injury and fibrosis in the MCD model ${ }^{106}$, suggesting that — in line with its presumed role in development ${ }^{145}$ — a primary role of caspase 8 in NASH is to prevent hyper-activation of necroptosis. By contrast, inhibition of RIPK3 in the MCD NASH model ameliorated liver injury and fibrosis ${ }^{106}$, providing evidence that necroptosis, not apoptosis, is the driver of liver injury and liver fibrosis in this well-established mouse model of NASH. Along with these findings in mice, a Western blot analysis of frozen liver tissue from a cohort of patients with biopsy-proven NASH showed that these patients had lower levels of intrahepatic caspase 3 cleavage than healthy individuals. However, patients with NASH had a dramatic upregulation of hepatic RIPK3 expression as an indicator of necroptosis ${ }^{106}$, suggesting a shift away from apoptotic towards necroptotic signalling in the livers of these patients.

Together, these data provide evidence that addition to apoptosis, necroptosis is a key regulatory pathway in human metabolic liver disease. Therefore, human NASH is one of the few human diseases in which activation of necroptosis has been suggested to be active in vivo without the concomitant inhibition of apoptosis. In line with this observation, it is interesting to note that RIPK3 knockout mice were also protected in a model of alcoholic liver disease ${ }^{107}$, providing further evidence for a predominant function of necroptosis as a 
metabolic cell death pathway in the liver. On the basis of these data, it seems important to revisit whether the efficacy of caspase inhibitors in NASH might be due to inhibition of caspase 1 and inflammasome activation rather than the inhibition of apoptosis. In summary, targeting necroptosis might represent a promising and specific therapeutic approach in human metabolic liver disease. However, further preclinical studies are needed to evaluate which parts of the pathway should be pharmacologically inhibited in which specific cellular compartment. Of note, inhibition of RIPK3 in a choline-deficient high-fat diet (CD-HFD) mouse model of NASH resulted in an aggravation of systemic insulin resistance and increased adipocyte apoptosis ${ }^{146}$, which suggests a compartment-specific protective function of RIPK3 in fat tissue and argues against RIPK3 as a drug target in patients with NASH. Conversely, targeting of caspase 8 in NASH might be problematic because of its potential to unleash the caspase 8-mediated suppression of necroptosis. In addition to blocking the execution of apoptosis or necroptosis through specific inhibitors, one could also envision targeting pathways that contribute to the activation of apoptosis or necroptosis in NASH. Experimental studies conducted primarily in mouse models that were published in the past few years have suggested that the ASK1-JNK pathway ${ }^{147-151}$, ER stress ${ }^{152}$ and the YAP paralogue TAZ ${ }^{153}$ are activated in NASH and that inhibiting ASK1-JNK and TAZ reduces cell death, NASH severity and NASH-induced fibrosis. Likewise, treatment with vitamin $\mathrm{E}^{154}$ or the FXR agonist obeticholic acid ${ }^{155}$ improved serum alanine aminotransferase levels in patients with NASH. However, only obeticholic acid improved liver fibrosis 154155 . Whether these interventions primarily affected apoptosis or necroptosis is not known.

\subsection{Liver cancer}

The development of HCC is the final, irreversible step in CLD and the most common cause of death in patients with compensated liver cirrhosis ${ }^{156}$. In turn, cell death is a fundamental driver of hepatocarcinogenesis. Elevated levels of circulating aminotransferases, a surrogate of hepatocyte cell death, are highly predictive for the development of liver cancer in patients ${ }^{157,158}$. Furthermore, there is increasing experimental evidence that programmed cell death pathways are key factors in hepatocarcinogenesis, but their specific functions might vary between the initiation of HCC versus later steps of tumour promotion. In most malignancies, defects in apoptosis are a key step in the malignant transformation of cells because apoptosis contributes to safeguarding genomic integrity ${ }^{159}$. Mice with conditional ablation of TAK1 and RIPK3 in parenchymal liver cells (hepatocytes and cholangiocytes) develop specific genetic alterations in these cells that render them insensitive to apoptotic cell death, which is an essential step of malignant transformation ${ }^{30}$. Moreover, stimulation of apoptosis can be a therapeutic approach in established cancers ${ }^{159}$; this method was demonstrated in an HCC mouse model using a tumour-targeted TRAIL fusion protein ${ }^{160}$. Notably all common human hepatoma cell lines such as Huh-7, HepG2 and Hep3B show a methylation-dependent loss of RIPK3 expression and thereby repress the activation of necroptosis ${ }^{161}$, which suggests that evasion from necroptosis is a similarly important step in the malignant transformation of HCC. Reestablishment of RIPK3 expression by demethylation of its promoter can re-sensitize tumour cell lines to chemotherapy ${ }^{161}$, suggesting that this approach is an interesting concept to increase the chemosensitivity of HCC, a tumour that normally does not respond to conventional chemotherapy ${ }^{162}$. 
Although evasion from cell death is a fundamental step in the process of malignant transformation, the induction of cell death is also an important initiating factor that initiates and fuels early stages of hepatocarcinogenesis. In experimental mouse models of liver cancer, deletion of a single survival gene such as Nemo or Tak1 from liver cells is sufficient to initiate a fatal sequence of spontaneous hepatocyte apoptosis, immune cell activation, compensatory hepatocyte proliferation, generation of oxidative stress and finally cancer development $29,31,106$. This unique relation between cell death and cancer is not seen in any other organ and corresponds to the fact that in human patients, liver cancer almost exclusively arises in a chronically damaged and inflamed liver ${ }^{4}$. A study published in 2017 identified a new apoptosis checkpoint controlled by the molecules RIPK1 and TRAF2 in an experimental mouse model, and found that low expression of RIPK1 and TRAF2 in patients with HCC undergoing resection or liver transplantation was predictive of poor prognosis ${ }^{37}$, further corroborating the fundamental role of apoptosis in human hepatocarcinogenesis.

The role of necroptosis in the context of hepatocarcinogenesis is less clear. Although clinical evidence for an initiator function of necroptosis in liver cancer does not exist to the best of our knowledge, the role of necroptosis was studied in one mouse model of Tak1 deletion in parenchymal liver cells. In this model, functional dissection of the specific contributions of apoptosis and necroptosis led to the surprising result that apoptosis strongly promoted cell death responses like inflammation, compensatory hepatocyte proliferation and carcinogenesis, whereas pure necroptosis activation suppressed inflammation, proliferation and carcinogenesis ${ }^{30}$. This unexpected finding is currently not well understood, but might be related to the specific molecular effects of Tak1 deletion on the reactivity of necroptotic cell death responses in the liver. Further studies are therefore needed to define specific DAMP and cytokine signatures that link apoptosis or necroptosis with the progression towards liver cancer. This knowledge could help identify new biomarker signatures to indicate the patients with chronic liver disease that are at high risk of developing cancer. Moreover, pharmacologically modifying responses to cell death might be a safer strategy when developing chemoprevention strategies than intervening at the level of cell death itself, given that the inhibition of one form of cell death increases the risk of activating alternative cell death forms under certain, potentially uncontrollable circumstances.

\section{TARGETING APOPTOSIS AND NECROPTOSIS}

Given that cell death has a fundamental role in almost all kinds of liver disease, the number of clinical trials that have assessed or are currently testing the pharmacological modification of cell death pathways in liver disease is somewhat limited. Most clinical trials have tested the inhibition of apoptosis in acute and chronic liver disease, on the basis of this cell death form having a more established role in liver disease than necroptosis. Emricasan is a first-inclass pan-caspase-inhibitor that was developed for the treatment of liver disease and tested in various pre-clinical models and clinical trials of hepatic disease ${ }^{163}$. In an initial trial published in 2003, emricasan injected four times a day for 7 days was relatively well tolerated and improved liver enzyme levels in patients with elevated circulating aspartate and alanine aminotransferase concentrations ${ }^{164}$. Since then, emricasan has been tested in several early phase clinical trials in distinct indications including liver preservation injury after transplantation ${ }^{165}$, chronic hepatitis C and NASH ${ }^{166,167}$ and improved liver enzyme levels 
in these indications. Current clinical trials are testing the effects of emricasan in patients with NASH fibrosis (NCT02686762), decompensated NASH cirrhosis (NCT03205345) and NASH cirrhosis with severe portal hypertension (NCT02960204), and a study in acute-onchronic liver failure (ACLF) was terminated (NCT02960204). Based on the controversial data on the pathophysiological roles of caspase 3 and especially caspase 8 in metabolic liver disease (see earlier discussion) and the implications for their targeting in NASH, it will be interesting to assess how much of the presumably protective function of pan-caspaseinhibitors in human NASH trials stems from the inhibition of caspases such as caspase 1 that are involved in inflammasome-related signaling, a pathway extremely important in NASH 168 . By contrast, the concept of apoptosis activation for the treatment of advanced hepatocellular carcinoma was tested in a phase II trial using an X-linked Inhibitor of Apoptosis (XIAP) antisense oligonucleotide (AEG35156) in combination with sorafenib ${ }^{169}$, which yielded a moderate increase in progression-free survival (4.0 months vs. 2.6 months), overall survival (6.5 months vs. 5.4 months) and objective response rates (16.1\% vs. 9.7\%) compared with Sorafenib alone.

To our best knowledge, no clinical trials have yet tested the inhibition of necroptosis in liver disease. Given the relatively recent discovery of this pathway and the many open questions regarding the molecular regulation of necroptosis and its biological function in distinct entities, it is not currently clear which molecule in this pathway is the best candidate to target, how it should be targeted and in which disease a clinical trial should be designed. In theory, necroptosis can be blocked on multiple levels, for instance by inhibiting RIPK1, RIPK3 or MLKL. Multiple molecular inhibitors for these molecules have been developed and patented, which include several generations of necrostatins (including Nec-1, Nec-2) that inhibit RIPK1; GSK'840, GSK'843 or GSK'872, which inhibit RIPK1 and RIPK3; and the MLKL inhibitor necrosulfonamide ${ }^{170}$. In addition, several natural products and isolated compounds exist with a known inhibitory function on necroptosis, such as curcumin and kongensin $\mathrm{A}^{171,172}$. On the basis of the data summarized above, NASH currently seems to be the liver disease with the highest clinical potential for inhibitors of necroptosis. As no specific NASH therapy has been clinically approved, the potential clinical benefit and economic incentive for performing a clinical trial in this setting is high. However, data showing a pro-diabetic effect of RIPK3 inhibition through promotion of adipose tissue inflammation in obese mice ${ }^{146}$ underlines that alternative targets to RIPK3 in the necroptosis pathway need to be tested in NASH, which might lead to a safe, efficient and specific therapeutic strategy in what is still an orphan disease.

Finally, it should be reemphasized that most experimental studies have examined cell death forms as independent entities, but their molecular machineries as well as response pathways are strongly interconnected and might be complementary in their effects on the organism, suggesting that targeting multiple cell death pathways might be more efficient than single therapy approaches ${ }^{173}$. On the basis of current experimental evidence, it is possible that a combinatorial inhibition of apoptosis and necroptosis in NASH could be an option to increase intervention efficiency and reduce the possible adverse effects of a compensatory activation of these pathways following single targeting of either apoptosis or necroptosis. Such an approach would certainly warrant more experimental knowledge of the long-term effects of necroptosis inhibition in humans and more studies in mouse models (for example 
in mice lacking both caspase 8 and RIPK3) to ensure that combined inhibition and escape from both pathways would not favour malignant transformation of hepatocytes in chronic inflammation. Also, it is conceivable that targeting pathways that enhance or protect from cell death, such as ASK1-JNK, FXR, ER stress, inflammation and the inflammasome might prove to be a better approach for NASH and other liver diseases rather than directly targeting the apoptotic or necroptotic machinery.

\section{CONCLUSIONS}

The discovery of programmed necrosis represented a paradigmatic change in our understanding of cell death and revitalized a whole field of research in inflammatory diseases. Although it seems that most forms of liver disease previously associated with necrotic cell death, such as DILI or ischaemia-reperfusion injury, are not mediated through necroptosis, increasing evidence suggests that necroptosis contributes to metabolic liver disease and could be a promising therapeutic target in NASH and alcoholic steatohepatitis. In order to bridge the gap towards clinical applications, several important questions remain to be resolved experimentally. Further research is needed to define the molecular contexts under which the necroptosis machinery truly mediates cell death of parenchymal cells versus just promoting inflammation without killing the cells. Moreover, whereas the mutual inhibitory interaction between apoptosis and necroptosis is well established, further experiments are warranted to explore the interactions of apoptosis or necroptosis with other cell-death related pathways, including autophagy, ferroptosis, pyroptosis and others, before targeting them in humans. Of note, most studies on necroptosis in the liver were performed using constitutive RIPK3 knockout mice. However, expression levels of RIPK3 in hepatocytes are relatively low, suggesting that important functions might exist in other cell types including biliary cells, hepatic stellate cells, Kupffer cells or endothelial cells, which could be unraveled by conditional knockout approaches. Finally, there is increasing evidence that distinct cell death forms might be linked with specific inflammatory response patterns. Understanding these patterns of mediators and specifically the DAMPs related to either apoptosis or necroptosis might not only be valuable for the development of biomarkers indicating the risk of decompensation in chronic liver disease. Given the strong interactions between distinct cell death pathways and the risk of activating one form of cell death by modulating another, targeting downstream pathways such as DAMPs or DAMP receptors is an alternative and possibly safer pharmacological strategy for the treatment of CLD.

\section{Acknowledgements:}

The authors would like to thank A.T. Schneider for her support in designing figures and M. Vucur for critically reading the manuscript. Work in the lab of R.F.S. was supported by NIH grants 5R01CA200597, 5R01CA190844, 1R01DK116620 and 5U01AA021912. Work in the lab of T.L. was supported by a Mildred-Scheel Endowed Professorship from the German Cancer Aid (Deutsche Krebshilfe), the German-Research-Foundation (DFG) (LU 1360/3-1 and SFB-TRR57 / P06), the Interdisciplinary-Centre-for-Clinical-Research (IZKF) Aachen-Germany and the Ernst-Jung-Foundation Hamburg.

\section{REFERENCES}

1. Michalopoulos GK \& DeFrances M Liver regeneration. Adv Biochem Eng Biotechnol 93, 101-134 (2005). [PubMed: 15791946] 
2. Benedetti A, Jezequel AM \& Orlandi F Preferential distribution of apoptotic bodies in acinar zone 3 of normal human and rat liver. J Hepatol 7, 319-324 (1988). [PubMed: 3235800]

3. Luedde T, Kaplowitz N \& Schwabe RF Cell death and cell death responses in liver disease: mechanisms and clinical relevance. Gastroenterology 147, 765-783 e764, doi:10.1053/j.gastro. 2014.07.018 (2014). [PubMed: 25046161]

4. Villanueva A \& Luedde T The transition from inflammation to cancer in the liver. Clinical Liver Disease 8, 89-93 (2016).

5. Schuppan D \& Afdhal NH Liver cirrhosis. Lancet 371, 838-851, doi:10.1016/ S0140-6736(08)60383-9 (2008). [PubMed: 18328931]

6. Wallach D, Kang TB, Dillon CP \& Green DR Programmed necrosis in inflammation: Toward identification of the effector molecules. Science 352, aaf2154, doi:10.1126/science.aaf2154 (2016). [PubMed: 27034377]

7. Yuan J, Najafov A \& Py BF Roles of Caspases in Necrotic Cell Death. Cell 167, 1693-1704, doi: 10.1016/j.cell.2016.11.047 (2016). [PubMed: 27984721]

8. Stockwell BR et al. Ferroptosis: A Regulated Cell Death Nexus Linking Metabolism, Redox Biology, and Disease. Cell 171, 273-285, doi:10.1016/j.cell.2017.09.021 (2017). [PubMed: 28985560]

9. Vande Walle L \& Lamkanfi M Pyroptosis. Curr Biol 26, R568-572, doi:10.1016/j.cub.2016.02.019 (2016). [PubMed: 27404251]

10. Fuchs Y \& Steller H Programmed cell death in animal development and disease. Cell 147, 742758, doi:10.1016/j.cell.2011.10.033 (2011). [PubMed: 22078876]

11. Galluzzi L, Lopez-Soto A, Kumar S \& Kroemer G Caspases Connect Cell-Death Signaling to Organismal Homeostasis. Immunity 44, 221-231, doi:10.1016/j.immuni.2016.01.020 (2016). [PubMed: 26885855]

12. Fan Y \& Bergmann A Apoptosis-induced compensatory proliferation. The Cell is dead. Long live the Cell! Trends Cell Biol 18, 467-473, doi:10.1016/j.tcb.2008.08.001 (2008). [PubMed: 18774295]

13. Jorgensen I, Rayamajhi M \& Miao EA Programmed cell death as a defence against infection. Nat Rev Immunol 17, 151-164, doi:10.1038/nri.2016.147 (2017). [PubMed: 28138137]

14. Linkermann A \& Green DR Necroptosis. N Engl J Med 370, 455-465, doi:10.1056/ NEJMra1310050 (2014). [PubMed: 24476434]

15. Louandre $\mathrm{C}$ et al. The retinoblastoma $(\mathrm{Rb})$ protein regulates ferroptosis induced by sorafenib in human hepatocellular carcinoma cells. Cancer Lett 356, 971-977, doi:10.1016/j.canlet. 2014.11.014 (2015). [PubMed: 25444922]

16. Wang $\mathrm{H}$ et al. Characterization of ferroptosis in murine models of hemochromatosis. Hepatology 66, 449-465, doi:10.1002/hep.29117 (2017). [PubMed: 28195347]

17. Wree A et al. NLRP3 inflammasome activation results in hepatocyte pyroptosis, liver inflammation, and fibrosis in mice. Hepatology 59, 898-910, doi:10.1002/hep.26592 (2014). [PubMed: 23813842]

18. Bialik S \& Kimchi A Lethal weapons: DAP-kinase, autophagy and cell death: DAP-kinase regulates autophagy. Curr Opin Cell Biol 22, 199-205, doi:10.1016/j.ceb.2009.11.004 (2010). [PubMed: 20005690]

19. Alegre F, Pelegrin P \& Feldstein AE Inflammasomes in Liver Fibrosis. Semin Liver Dis 37, 119 127, doi:10.1055/s-0037-1601350 (2017). [PubMed: 28564720]

20. Angeli JPF, Shah R, Pratt DA \& Conrad M Ferroptosis Inhibition: Mechanisms and Opportunities. Trends Pharmacol Sci 38, 489-498, doi:10.1016/j.tips.2017.02.005 (2017). [PubMed: 28363764]

21. Majno G \& Joris I Apoptosis, oncosis, and necrosis. An overview of cell death. Am J Pathol 146, 3-15 (1995). [PubMed: 7856735]

22. Van Cruchten S \& Van Den Broeck W Morphological and biochemical aspects of apoptosis, oncosis and necrosis. Anat Histol Embryol 31, 214-223 (2002). [PubMed: 12196263]

23. Malhi H, Gores GJ \& Lemasters JJ Apoptosis and necrosis in the liver: a tale of two deaths? Hepatology 43, S31-44, doi:10.1002/hep.21062 (2006). [PubMed: 16447272] 
24. Davidovich P, Kearney CJ \& Martin SJ Inflammatory outcomes of apoptosis, necrosis and necroptosis. Biol Chem 395, 1163-1171, doi:10.1515/hsz-2014-0164 (2014). [PubMed: 25153241]

25. McIlwain DR, Berger T \& Mak TW Caspase functions in cell death and disease. Cold Spring Harb Perspect Biol 5, a008656, doi:10.1101/cshperspect.a008656 (2013). [PubMed: 23545416]

26. Liedtke C \& Trautwein C The role of TNF and Fas dependent signaling in animal models of inflammatory liver injury and liver cancer. Eur J Cell Biol 91, 582-589, doi:10.1016/j.ejcb. 2011.10.001 (2012). [PubMed: 22153863]

27. Schwabe RF \& Brenner DA Mechanisms of Liver Injury. I. TNF-alpha-induced liver injury: role of IKK, JNK, and ROS pathways. Am J Physiol Gastrointest Liver Physiol 290, G583-589, doi: 10.1152/ajpgi.00422.2005 (2006). [PubMed: 16537970]

28. Dondelinger Y, Darding M, Bertrand MJ \& Walczak H Poly-ubiquitination in TNFR1-mediated necroptosis. Cell Mol Life Sci 73, 2165-2176, doi:10.1007/s00018-016-2191-4 (2016). [PubMed: 27066894]

29. Bettermann K et al. TAK1 suppresses a NEMO-dependent but NF-kappaB-independent pathway to liver cancer. Cancer Cell 17, 481-496, doi:10.1016/j.ccr.2010.03.021 (2010). [PubMed: 20478530]

30. Vucur M et al. RIP3 inhibits inflammatory hepatocarcinogenesis but promotes cholestasis by controlling caspase-8- and JNK-dependent compensatory cell proliferation. Cell Rep 4, 776-790, doi:10.1016/j.celrep.2013.07.035 (2013). [PubMed: 23972991]

31. Luedde $\mathrm{T}$ et al. Deletion of NEMO/IKKgamma in liver parenchymal cells causes steatohepatitis and hepatocellular carcinoma. Cancer Cell 11, 119-132, doi:10.1016/j.ccr.2006.12.016 (2007). [PubMed: 17292824]

32. Kondylis V et al. NEMO Prevents Steatohepatitis and Hepatocellular Carcinoma by Inhibiting RIPK1 Kinase Activity-Mediated Hepatocyte Apoptosis. Cancer Cell 28, 582-598, doi:10.1016/ j.ccell.2015.10.001 (2015). [PubMed: 26555174]

33. Luedde $\mathrm{T}$ et al. IKK1 and IKK 2 cooperate to maintain bile duct integrity in the liver. Proc Natl Acad Sci U S A 105, 9733-9738, doi:10.1073/pnas.0800198105 (2008). [PubMed: 18606991]

34. Yin XM \& Ding WX Death receptor activation-induced hepatocyte apoptosis and liver injury. Curr Mol Med 3, 491-508 (2003). [PubMed: 14527081]

35. Guicciardi ME, Malhi H, Mott JL \& Gores GJ Apoptosis and necrosis in the liver. Compr Physiol 3, 977-1010, doi:10.1002/cphy.c120020 (2013). [PubMed: 23720337]

36. Koppe $\mathrm{C}$ et al. IkappaB kinasealpha/beta control biliary homeostasis and hepatocarcinogenesis in mice by phosphorylating the cell-death mediator receptor-interacting protein kinase 1. Hepatology 64, 1217-1231, doi:10.1002/hep.28723 (2016). [PubMed: 27396433]

37. Schneider AT et al. RIPK1 Suppresses a TRAF2-Dependent Pathway to Liver Cancer. Cancer Cell 31, 94-109, doi:10.1016/j.ccell.2016.11.009 (2017). [PubMed: 28017612]

38. Vucur M, Schneider AT, Gautheron J \& Luedde T The enigma of RIPK1 in the liver: More than just a kinase. Mol Cell Oncol 4, e1304191, doi:10.1080/23723556.2017.1304191 (2017). [PubMed: 28616581]

39. Laster SM, Wood JG \& Gooding LR Tumor necrosis factor can induce both apoptic and necrotic forms of cell lysis. J Immunol 141, 2629-2634 (1988). [PubMed: 3171180]

40. Vercammen D et al. Inhibition of caspases increases the sensitivity of L929 cells to necrosis mediated by tumor necrosis factor. J Exp Med 187, 1477-1485 (1998). [PubMed: 9565639]

41. Holler $\mathrm{N}$ et al. Fas triggers an alternative, caspase-8-independent cell death pathway using the kinase RIP as effector molecule. Nat Immunol 1, 489-495, doi:10.1038/82732 (2000). [PubMed: 11101870]

42. Degterev A et al. Chemical inhibitor of nonapoptotic cell death with therapeutic potential for ischemic brain injury. Nat Chem Biol 1, 112-119, doi:10.1038/nchembio711 (2005). [PubMed: 16408008]

43. Zhang DW et al. RIP3, an energy metabolism regulator that switches TNF-induced cell death from apoptosis to necrosis. Science 325, 332-336, doi:10.1126/science.1172308 (2009). [PubMed: 19498109]

44. He S et al. Receptor interacting protein kinase-3 determines cellular necrotic response to TNFalpha. Cell 137, 1100-1111, doi:10.1016/j.cell.2009.05.021 (2009). [PubMed: 19524512] 
45. Cho YS et al. Phosphorylation-driven assembly of the RIP1-RIP3 complex regulates programmed necrosis and virus-induced inflammation. Cell 137, 1112-1123, doi:10.1016/j.cell.2009.05.037 (2009). [PubMed: 19524513]

46. Sun L et al. Mixed lineage kinase domain-like protein mediates necrosis signaling downstream of RIP3 kinase. Cell 148, 213-227, doi:10.1016/j.cell.2011.11.031 (2012). [PubMed: 22265413]

47. Gong YN, Guy C, Crawford JC \& Green DR Biological events and molecular signaling following MLKL activation during necroptosis. Cell Cycle 16, 1748-1760, doi: 10.1080/15384101.2017.1371889 (2017). [PubMed: 28854080]

48. Newton K et al. Activity of protein kinase RIPK3 determines whether cells die by necroptosis or apoptosis. Science 343, 1357-1360, doi:10.1126/science.1249361 (2014). [PubMed: 24557836]

49. Tummers B \& Green DR Caspase-8: regulating life and death. Immunol Rev 277, 76-89, doi: 10.1111/imr.12541 (2017). [PubMed: 28462525]

50. Ravichandran KS Beginnings of a good apoptotic meal: the find-me and eat-me signaling pathways. Immunity 35, 445-455, doi:10.1016/j.immuni.2011.09.004 (2011). [PubMed: 22035837]

51. Martin SJ, Henry CM \& Cullen SP A perspective on mammalian caspases as positive and negative regulators of inflammation. Mol Cell 46, 387-397, doi:10.1016/j.molcel.2012.04.026 (2012). [PubMed: 22633487]

52. Bosurgi L, Hughes LD, Rothlin CV \& Ghosh S Death begets a new beginning. Immunol Rev 280, 8-25, doi:10.1111/imr.12585 (2017). [PubMed: 29027219]

53. Kaczmarek A, Vandenabeele P \& Krysko DV Necroptosis: the release of damage-associated molecular patterns and its physiological relevance. Immunity 38, 209-223, doi:10.1016/j.immuni. 2013.02.003 (2013). [PubMed: 23438821]

54. Kumar S, Calianese D \& Birge RB Efferocytosis of dying cells differentially modulate immunological outcomes in tumor microenvironment. Immunol Rev 280, 149-164, doi:10.1111/ imr.12587 (2017). [PubMed: 29027226]

55. Lemasters JJ Dying a thousand deaths: redundant pathways from different organelles to apoptosis and necrosis. Gastroenterology 129, 351-360 (2005). [PubMed: 16012960]

56. Matzinger P The danger model: a renewed sense of self. Science 296, 301-305, doi:10.1126/ science.1071059 (2002). [PubMed: 11951032]

57. Kang TB, Yang SH, Toth B, Kovalenko A \& Wallach D Caspase-8 blocks kinase RIPK3-mediated activation of the NLRP3 inflammasome. Immunity 38, 27-40, doi:10.1016/j.immuni.2012.09.015 (2013). [PubMed: 23260196]

58. Lawlor KE et al. RIPK3 promotes cell death and NLRP3 inflammasome activation in the absence of MLKL. Nat Commun 6, 6282, doi:10.1038/ncomms7282 (2015). [PubMed: 25693118]

59. Moriwaki K, Bertin J, Gough PJ \& Chan FK A RIPK3-caspase 8 complex mediates atypical proIL-1beta processing. J Immunol 194, 1938-1944, doi:10.4049/jimmunol.1402167 (2015). [PubMed: 25567679]

60. Seki E \& Schwabe RF Hepatic inflammation and fibrosis: functional links and key pathways. Hepatology 61, 1066-1079, doi:10.1002/hep.27332 (2015). [PubMed: 25066777]

61. Zhan SS et al. Phagocytosis of apoptotic bodies by hepatic stellate cells induces NADPH oxidase and is associated with liver fibrosis in vivo. Hepatology 43, 435-443, doi:10.1002/hep.21093 (2006). [PubMed: 16496318]

62. Canbay A et al. Apoptotic body engulfment by a human stellate cell line is profibrogenic. Lab Invest 83, 655-663 (2003). [PubMed: 12746475]

63. Affo S, Yu LX \& Schwabe RF The Role of Cancer-Associated Fibroblasts and Fibrosis in Liver Cancer. Annu Rev Pathol 12, 153-186, doi:10.1146/annurev-pathol-052016-100322 (2017). [PubMed: 27959632]

64. Sun B \& Karin M Inflammation and liver tumorigenesis. Front Med 7, 242-254, doi:10.1007/ s11684-013-0256-4 (2013). [PubMed: 23681888]

65. Michalopoulos GK \& DeFrances MC Liver regeneration. Science 276, 60-66 (1997). [PubMed: 9082986] 
66. Schaub JR, Malato Y, Gormond C \& Willenbring H Evidence against a stem cell origin of new hepatocytes in a common mouse model of chronic liver injury. Cell Rep 8, 933-939, doi:10.1016/ j.celrep.2014.07.003 (2014). [PubMed: 25131204]

67. Malato $\mathrm{Y}$ et al. Fate tracing of mature hepatocytes in mouse liver homeostasis and regeneration. J Clin Invest 121, 4850-4860, doi:10.1172/JCI59261 (2011). [PubMed: 22105172]

68. Yanger $\mathrm{K}$ et al. Adult hepatocytes are generated by self-duplication rather than stem cell differentiation. Cell Stem Cell 15, 340-349, doi:10.1016/j.stem.2014.06.003 (2014). [PubMed: 25130492]

69. Sharpless NE \& DePinho RA How stem cells age and why this makes us grow old. Nat Rev Mol Cell Biol 8, 703-713, doi:10.1038/nrm2241 (2007). [PubMed: 17717515]

70. Morrison SJ \& Kimble J Asymmetric and symmetric stem-cell divisions in development and cancer. Nature 441, 1068-1074, doi:10.1038/nature04956 (2006). [PubMed: 16810241]

71. Boege $Y$ et al. A Dual Role of Caspase-8 in Triggering and Sensing Proliferation-Associated DNA Damage, a Key Determinant of Liver Cancer Development. Cancer Cell 32, 342-359 e310, doi: 10.1016/j.ccell.2017.08.010 (2017). [PubMed: 28898696]

72. Galluzzi L, Buque A, Kepp O, Zitvogel L \& Kroemer G Immunological Effects of Conventional Chemotherapy and Targeted Anticancer Agents. Cancer Cell 28, 690-714, doi:10.1016/j.ccell. 2015.10.012 (2015). [PubMed: 26678337]

73. Garg AD \& Agostinis P Cell death and immunity in cancer: From danger signals to mimicry of pathogen defense responses. Immunol Rev 280, 126-148, doi:10.1111/imr.12574 (2017). [PubMed: 29027218]

74. Krysko O et al. Necroptotic cell death in anti-cancer therapy. Immunol Rev 280, 207-219, doi: 10.1111/imr.12583 (2017). [PubMed: 29027225]

75. Beutler B Neo-ligands for innate immune receptors and the etiology of sterile inflammatory disease. Immunol Rev 220, 113-128, doi:10.1111/j.1600-065X.2007.00577.x (2007). [PubMed: 17979843]

76. Weerasinghe SV, Park MJ, Portney DA \& Omary MB Mouse genetic background contributes to hepatocyte susceptibility to Fas-mediated apoptosis. Mol Biol Cell 27, 3005-3012, doi:10.1091/ mbc.E15-06-0423 (2016). [PubMed: 27535425]

77. Bai L \& Wang S Targeting apoptosis pathways for new cancer therapeutics. Annu Rev Med 65, 139-155, doi:10.1146/annurev-med-010713-141310 (2014). [PubMed: 24188661]

78. Hernandez $\mathrm{C}$ et al. HMGB1 links chronic liver injury to progenitor responses and hepatocarcinogenesis. J Clin Invest 128, 2436-2451, doi:10.1172/JCI91786 (2018). [PubMed: 29558367]

79. Huebener $P$ et al. The HMGB1/RAGE axis triggers neutrophil-mediated injury amplification following necrosis. J Clin Invest 125, 539-550, doi:10.1172/JCI76887 (2015). [PubMed: 25562324]

80. Scaffidi P, Misteli T \& Bianchi ME Release of chromatin protein HMGB1 by necrotic cells triggers inflammation. Nature 418, 191-195, doi:10.1038/nature00858 (2002). [PubMed: 12110890]

81. Arriazu E et al. Signalling via the osteopontin and high mobility group box-1 axis drives the fibrogenic response to liver injury. Gut 66, 1123-1137, doi:10.1136/gutjnl-2015-310752 (2017). [PubMed: 26818617]

82. Khambu B et al. HMGB1 promotes ductular reaction and tumorigenesis in autophagy-deficient livers. J Clin Invest 128, 2419-2435 (2018). [PubMed: 29558368]

83. McDonald B et al. Intravascular danger signals guide neutrophils to sites of sterile inflammation. Science 330, 362-366, doi:10.1126/science.1195491 (2010). [PubMed: 20947763]

84. Savio LEB et al. CD39 limits P2X7 receptor inflammatory signaling and attenuates sepsis-induced liver injury. J Hepatol 67, 716-726, doi:10.1016/j.jhep.2017.05.021 (2017). [PubMed: 28554875]

85 . Hoque $\mathrm{R}$ et al. $\mathrm{P} 2 \mathrm{X} 7$ receptor-mediated purinergic signaling promotes liver injury in acetaminophen hepatotoxicity in mice. Am J Physiol Gastrointest Liver Physiol 302, G1171-1179, doi:10.1152/ajpgi.00352.2011 (2012). [PubMed: 22383490] 
86. Kataoka H, Kono H, Patel Z, Kimura Y \& Rock KL Evaluation of the contribution of multiple DAMPs and DAMP receptors in cell death-induced sterile inflammatory responses. PLoS One 9, e104741, doi:10.1371/journal.pone.0104741 (2014). [PubMed: 25127469]

87. Marques PE et al. Chemokines and mitochondrial products activate neutrophils to amplify organ injury during mouse acute liver failure. Hepatology 56, 1971-1982, doi:10.1002/hep.25801 (2012). [PubMed: 22532075]

88. Liu M et al. Formylpeptide receptors are critical for rapid neutrophil mobilization in host defense against Listeria monocytogenes. Sci Rep 2, 786, doi:10.1038/srep00786 (2012). [PubMed: 23139859]

89. Watanabe A et al. Apoptotic hepatocyte DNA inhibits hepatic stellate cell chemotaxis via toll-like receptor 9. Hepatology 46, 1509-1518, doi:10.1002/hep.21867 (2007). [PubMed: 17705260]

90. Luthi AU et al. Suppression of interleukin-33 bioactivity through proteolysis by apoptotic caspases. Immunity 31, 84-98, doi:10.1016/j.immuni.2009.05.007 (2009). [PubMed: 19559631]

91. Cayrol C \& Girard JP The IL-1-like cytokine IL-33 is inactivated after maturation by caspase-1. Proc Natl Acad Sci U S A 106, 9021-9026, doi:10.1073/pnas.0812690106 (2009). [PubMed: 19439663]

92. Rickard JA et al. RIPK1 regulates RIPK3-MLKL-driven systemic inflammation and emergency hematopoiesis. Cell 157, 1175-1188, doi:10.1016/j.cell.2014.04.019 (2014). [PubMed: 24813849]

93. Rankin AL et al. IL-33 induces IL-13-dependent cutaneous fibrosis. J Immunol 184, 1526-1535, doi:10.4049/jimmunol.0903306 (2010). [PubMed: 20042577]

94. Vannella KM et al. Combinatorial targeting of TSLP, IL-25, and IL-33 in type 2 cytokine-driven inflammation and fibrosis. Sci Transl Med 8, 337ra365, doi:10.1126/scitranslmed.aaf1938 (2016).

95. McHedlidze T et al. Interleukin-33-dependent innate lymphoid cells mediate hepatic fibrosis. Immunity 39, 357-371, doi:10.1016/j.immuni.2013.07.018 (2013). [PubMed: 23954132]

96. Tan $\mathrm{Z}$ et al. Interleukin-33 drives hepatic fibrosis through activation of hepatic stellate cells. Cell Mol Immunol, doi:10.1038/cmi.2016.63 (2017).

97. Vasseur $\mathrm{P}$ et al. Endogenous IL-33 has no effect on the progression of fibrosis during experimental steatohepatitis. Oncotarget 8, 48563-48574, doi:10.18632/oncotarget.18335 (2017). [PubMed: 28611297]

98. Shi Y, Evans JE \& Rock KL Molecular identification of a danger signal that alerts the immune system to dying cells. Nature 425, 516-521, doi:10.1038/nature01991 (2003). [PubMed: 14520412]

99. Martinon F, Petrilli V, Mayor A, Tardivel A \& Tschopp J Gout-associated uric acid crystals activate the NALP3 inflammasome. Nature 440, 237-241, doi:10.1038/nature04516 (2006). [PubMed: 16407889]

100. Watanabe A et al. Inflammasome-mediated regulation of hepatic stellate cells. Am J Physiol Gastrointest Liver Physiol 296, G1248-1257, doi:10.1152/ajpgi.90223.2008 (2009). [PubMed: 19359429]

101. Labat-Moleur F et al. TUNEL apoptotic cell detection in tissue sections: critical evaluation and improvement. J Histochem Cytochem 46, 327-334, doi:10.1177/002215549804600306 (1998). [PubMed: 9487114]

102. Wieckowska A et al. In vivo assessment of liver cell apoptosis as a novel biomarker of disease severity in nonalcoholic fatty liver disease. Hepatology 44, 27-33, doi:10.1002/hep.21223 (2006). [PubMed: 16799979]

103. Tamimi TI et al. An apoptosis panel for nonalcoholic steatohepatitis diagnosis. J Hepatol 54, 1224-1229, doi:10.1016/j.jhep.2010.08.023 (2011). [PubMed: 21145805]

104. Mazzolini G, Sowa JP \& Canbay A Cell death mechanisms in human chronic liver diseases: a far cry from clinical applicability. Clin Sci (Lond) 130, 2121-2138, doi:10.1042/CS20160035 (2016). [PubMed: 27798227]

105. Wang $\mathrm{H}$ et al. Mixed lineage kinase domain-like protein MLKL causes necrotic membrane disruption upon phosphorylation by RIP3. Mol Cell 54, 133-146, doi:10.1016/j.molcel. 2014.03.003 (2014). [PubMed: 24703947] 
106. Gautheron J et al. A positive feedback loop between RIP3 and JNK controls non-alcoholic steatohepatitis. EMBO Mol Med 6, 1062-1074, doi:10.15252/emmm.201403856 (2014). [PubMed: 24963148]

107. Roychowdhury S, McMullen MR, Pisano SG, Liu X \& Nagy LE Absence of receptor interacting protein kinase 3 prevents ethanol-induced liver injury. Hepatology 57, 1773-1783, doi:10.1002/ hep.26200 (2013). [PubMed: 23319235]

108. Gong YN et al. ESCRT-III Acts Downstream of MLKL to Regulate Necroptotic Cell Death and Its Consequences. Cell 169, 286-300 e216, doi:10.1016/j.cell.2017.03.020 (2017). [PubMed: 28388412]

109. Yoon S, Kovalenko A, Bogdanov K \& Wallach D MLKL, the Protein that Mediates Necroptosis, Also Regulates Endosomal Trafficking and Extracellular Vesicle Generation. Immunity 47, 5165 e57, doi:10.1016/j.immuni.2017.06.001 (2017). [PubMed: 28666573]

110. Panayotova-Dimitrova D et al. cFLIP regulates skin homeostasis and protects against TNFinduced keratinocyte apoptosis. Cell Rep 5, 397-408, doi:10.1016/j.celrep.2013.09.035 (2013). [PubMed: 24209745]

111. Strilic B et al. Tumour-cell-induced endothelial cell necroptosis via death receptor 6 promotes metastasis. Nature 536, 215-218, doi:10.1038/nature19076 (2016). [PubMed: 27487218]

112. de Graaf IA et al. Preparation and incubation of precision-cut liver and intestinal slices for application in drug metabolism and toxicity studies. Nat Protoc 5, 1540-1551, doi:10.1038/nprot. 2010.111 (2010). [PubMed: 20725069]

113. Vasilikos L, Spilgies LM, Knop J \& Wong WW Regulating the balance between necroptosis, apoptosis and inflammation by inhibitors of apoptosis proteins. Immunol Cell Biol 95, 160-165, doi:10.1038/icb.2016.118 (2017). [PubMed: 27904150]

114. Wu YT et al. zVAD-induced necroptosis in L929 cells depends on autocrine production of TNFalpha mediated by the PKC-MAPKs-AP-1 pathway. Cell Death Differ 18, 26-37, doi: 10.1038/cdd.2010.72 (2011). [PubMed: 20539307]

115. Krenkel O, Mossanen JC \& Tacke F Immune mechanisms in acetaminophen-induced acute liver failure. Hepatobiliary Surg Nutr 3, 331-343, doi:10.3978/j.issn.2304-3881.2014.11.01 (2014). [PubMed: 25568858]

116. Schneider AT, Gautheron J, Tacke F, Vucur M \& Luedde T Receptor interacting protein kinase 1 (RIPK1) in hepatocytes does not mediate murine acetaminophen toxicity. Hepatology 64, 306308, doi:10.1002/hep.28225 (2016).

117. Takemoto K et al. Necrostatin-1 protects against reactive oxygen species (ROS)-induced hepatotoxicity in acetaminophen-induced acute liver failure. FEBS Open Bio 4, 777-787, doi: 10.1016/j.fob.2014.08.007 (2014).

118. Dara L et al. Receptor interacting protein kinase 1 mediates murine acetaminophen toxicity independent of the necrosome and not through necroptosis. Hepatology 62, 1847-1857, doi: 10.1002/hep.27939 (2015). [PubMed: 26077809]

119. Deutsch M et al. Divergent effects of RIP1 or RIP3 blockade in murine models of acute liver injury. Cell Death Dis 6, e1759, doi:10.1038/cddis.2015.126 (2015). [PubMed: 25950489]

120. Li JX et al. The B-Raf(V600E) inhibitor dabrafenib selectively inhibits RIP3 and alleviates acetaminophen-induced liver injury. Cell Death Dis 5, e1278, doi:10.1038/cddis.2014.241 (2014). [PubMed: 24901049]

121. Ramachandran A et al. Receptor interacting protein kinase 3 is a critical early mediator of acetaminophen-induced hepatocyte necrosis in mice. Hepatology 58, 2099-2108, doi:10.1002/ hep.26547 (2013). [PubMed: 23744808]

122. Takahashi $\mathrm{N}$ et al. Necrostatin-1 analogues: critical issues on the specificity, activity and in vivo use in experimental disease models. Cell Death Dis 3, e437, doi:10.1038/cddis.2012.176 (2012). [PubMed: 23190609]

123. Wang K Molecular mechanisms of liver injury: apoptosis or necrosis. Exp Toxicol Pathol 66, 351-356, doi:10.1016/j.etp.2014.04.004 (2014). [PubMed: 24867271]

124. Friedmann Angeli JP et al. Inactivation of the ferroptosis regulator Gpx4 triggers acute renal failure in mice. Nat Cell Biol 16, 1180-1191, doi:10.1038/ncb3064 (2014). [PubMed: 25402683] 
125. Khan HA, Ahmad MZ, Khan JA \& Arshad MI Crosstalk of liver immune cells and cell death mechanisms in different murine models of liver injury and its clinical relevance. Hepatobiliary Pancreat Dis Int 16, 245-256 (2017). [PubMed: 28603092]

126. Gunther $\mathrm{C}$ et al. The pseudokinase MLKL mediates programmed hepatocellular necrosis independently of RIPK3 during hepatitis. J Clin Invest 126, 4346-4360, doi:10.1172/JCI87545 (2016). [PubMed: 27756058]

127. Filliol A et al. RIPK1 protects from TNF-alpha-mediated liver damage during hepatitis. Cell Death Dis 7, e2462, doi:10.1038/cddis.2016.362 (2016). [PubMed: 27831558]

128. Herrmann $\mathrm{O}$ et al. IKK mediates ischemia-induced neuronal death. Nat Med 11, 1322-1329, doi: 10.1038/nm1323 (2005). [PubMed: 16286924]

129. Linkermann A et al. Necroptosis in immunity and ischemia-reperfusion injury. Am J Transplant 13, 2797-2804, doi:10.1111/ajt.12448 (2013). [PubMed: 24103029]

130. Luedde $\mathrm{M}$ et al. RIP3, a kinase promoting necroptotic cell death, mediates adverse remodelling after myocardial infarction. Cardiovasc Res 103, 206-216, doi:10.1093/cvr/cvu146 (2014). [PubMed: 24920296]

131. Singh S, Osna NA \& Kharbanda KK Treatment options for alcoholic and non-alcoholic fatty liver disease: A review. World J Gastroenterol 23, 6549-6570, doi:10.3748/wjg.v23.i36.6549 (2017). [PubMed: 29085205]

132. Tsochatzis EA \& Newsome PN Non-alcoholic fatty liver disease and the interface between primary and secondary care. Lancet Gastroenterol Hepatol 3, 509-517, doi:10.1016/ S2468-1253(18)30077-3 (2018). [PubMed: 29893235]

133. Cobbina E \& Akhlaghi F Non-alcoholic fatty liver disease (NAFLD) - pathogenesis, classification, and effect on drug metabolizing enzymes and transporters. Drug Metab Rev 49, 197-211, doi:10.1080/03602532.2017.1293683 (2017). [PubMed: 28303724]

134. Diehl AM \& Day C Cause, Pathogenesis, and Treatment of Nonalcoholic Steatohepatitis. N Engl J Med 377, 2063-2072, doi:10.1056/NEJMra1503519 (2017). [PubMed: 29166236]

135. Day CP \& James OF Steatohepatitis: a tale of two "hits"? Gastroenterology 114, 842-845 (1998). [PubMed: 9547102]

136. Buzzetti E, Pinzani M \& Tsochatzis EA The multiple-hit pathogenesis of non-alcoholic fatty liver disease (NAFLD). Metabolism 65, 1038-1048, doi:10.1016/j.metabol.2015.12.012 (2016). [PubMed: 26823198]

137. Feldstein AE et al. Hepatocyte apoptosis and fas expression are prominent features of human nonalcoholic steatohepatitis. Gastroenterology 125, 437-443 (2003). [PubMed: 12891546]

138. Thapaliya $\mathrm{S}$ et al. Caspase 3 inactivation protects against hepatic cell death and ameliorates fibrogenesis in a diet-induced NASH model. Dig Dis Sci 59, 1197-1206, doi:10.1007/ s10620-014-3167-6 (2014). [PubMed: 24795036]

139. Alkhouri N, Carter-Kent C \& Feldstein AE Apoptosis in nonalcoholic fatty liver disease: diagnostic and therapeutic implications. Expert Rev Gastroenterol Hepatol 5, 201-212, doi: 10.1586/egh.11.6 (2011). [PubMed: 21476915]

140. Witek RP et al. Pan-caspase inhibitor VX-166 reduces fibrosis in an animal model of nonalcoholic steatohepatitis. Hepatology 50, 1421-1430, doi:10.1002/hep.23167 (2009). [PubMed: 19676126]

141. Ratziu V et al. A phase 2, randomized, double-blind, placebo-controlled study of GS-9450 in subjects with nonalcoholic steatohepatitis. Hepatology 55, 419-428, doi:10.1002/hep.24747 (2012). [PubMed: 22006541]

142. US National Library of Medicine. ClinicalTrials.gov https://clinicaltrials.gov/ct2/show/ NCT02960204 (2018).

143. Malhi H \& Gores GJ Molecular mechanisms of lipotoxicity in nonalcoholic fatty liver disease. Semin Liver Dis 28, 360-369, doi:10.1055/s-0028-1091980 (2008). [PubMed: 18956292]

144. Volkmann $\mathrm{X}$ et al. Caspase activation is associated with spontaneous recovery from acute liver failure. Hepatology 47, 1624-1633, doi:10.1002/hep.22237 (2008). [PubMed: 18393389]

145. Kaiser WJ et al. RIP3 mediates the embryonic lethality of caspase-8-deficient mice. Nature 471, 368-372, doi:10.1038/nature09857 (2011). [PubMed: 21368762] 
146. Gautheron J et al. The necroptosis-inducing kinase RIPK3 dampens adipose tissue inflammation and glucose intolerance. Nat Commun 7, 11869, doi:10.1038/ncomms11869 (2016). [PubMed: 27323669]

147. Malhi H, Bronk SF, Werneburg NW \& Gores GJ Free fatty acids induce JNK-dependent hepatocyte lipoapoptosis. J Biol Chem 281, 12093-12101, doi:10.1074/jbc.M510660200 (2006). [PubMed: 16505490]

148. Zhang W et al. Tumor necrosis factor-alpha accelerates apoptosis of steatotic hepatocytes from a murine model of non-alcoholic fatty liver disease. Biochem Biophys Res Commun 391, 17311736, doi:10.1016/j.bbrc.2009.12.144 (2010). [PubMed: 20043871]

149. Xiang M et al. Targeting hepatic TRAF1-ASK1 signaling to improve inflammation, insulin resistance, and hepatic steatosis. J Hepatol 64, 1365-1377, doi:10.1016/j.jhep.2016.02.002 (2016). [PubMed: 26860405]

150. Wang PX et al. Targeting CASP8 and FADD-like apoptosis regulator ameliorates nonalcoholic steatohepatitis in mice and nonhuman primates. Nat Med 23, 439-449, doi:10.1038/nm.4290 (2017). [PubMed: 28218919]

151. Zhang $P$ et al. The deubiquitinating enzyme TNFAIP3 mediates inactivation of hepatic ASK1 and ameliorates nonalcoholic steatohepatitis. Nat Med 24, 84-94, doi:10.1038/nm.4453 (2018). [PubMed: 29227477]

152. Nakagawa $\mathrm{H}$ et al. ER stress cooperates with hypernutrition to trigger TNF-dependent spontaneous HCC development. Cancer Cell 26, 331-343, doi:10.1016/j.ccr.2014.07.001 (2014). [PubMed: 25132496]

153. Wang $X$ et al. Hepatocyte TAZ/WWTR1 Promotes Inflammation and Fibrosis in Nonalcoholic Steatohepatitis. Cell Metab 24, 848-862, doi:10.1016/j.cmet.2016.09.016 (2016). [PubMed: 28068223]

154. Sanyal AJ et al. Pioglitazone, vitamin E, or placebo for nonalcoholic steatohepatitis. N Engl J Med 362, 1675-1685, doi:10.1056/NEJMoa0907929 (2010). [PubMed: 20427778]

155. Neuschwander-Tetri BA et al. Farnesoid X nuclear receptor ligand obeticholic acid for noncirrhotic, non-alcoholic steatohepatitis (FLINT): a multicentre, randomised, placebo-controlled trial. Lancet 385, 956-965, doi:10.1016/S0140-6736(14)61933-4 (2015). [PubMed: 25468160]

156. Benvegnu L, Gios M, Boccato S \& Alberti A Natural history of compensated viral cirrhosis: a prospective study on the incidence and hierarchy of major complications. Gut 53, 744-749 (2004). [PubMed: 15082595]

157. Wen CP et al. Hepatocellular carcinoma risk prediction model for the general population: the predictive power of transaminases. J Natl Cancer Inst 104, 1599-1611, doi:10.1093/jnci/djs372 (2012). [PubMed: 23073549]

158. Yang HI et al. Risk estimation for hepatocellular carcinoma in chronic hepatitis B (REACH-B): development and validation of a predictive score. Lancet Oncol 12, 568-574, doi:10.1016/ S1470-2045(11)70077-8 (2011). [PubMed: 21497551]

159. Hassan M, Watari H, AbuAlmaaty A, Ohba Y \& Sakuragi N Apoptosis and molecular targeting therapy in cancer. Biomed Res Int 2014, 150845, doi:10.1155/2014/150845 (2014). [PubMed: 25013758]

160. Wahl K et al. Increased apoptosis induction in hepatocellular carcinoma by a novel tumor-targeted TRAIL fusion protein combined with bortezomib. Hepatology 57, 625-636, doi:10.1002/hep. 26082 (2013). [PubMed: 22991197]

161. Koo GB et al. Methylation-dependent loss of RIP3 expression in cancer represses programmed necrosis in response to chemotherapeutics. Cell Res 25, 707-725, doi:10.1038/cr.2015.56 (2015). [PubMed: 25952668]

162. Deng GL, Zeng S \& Shen H Chemotherapy and target therapy for hepatocellular carcinoma: New advances and challenges. World J Hepatol 7, 787-798, doi:10.4254/wjh.v7.i5.787 (2015). [PubMed: 25914779]

163. Linton SD et al. First-in-class pan caspase inhibitor developed for the treatment of liver disease. J Med Chem 48, 6779-6782, doi:10.1021/jm050307e (2005). [PubMed: 16250635] 
164. Valentino KL, Gutierrez M, Sanchez R, Winship MJ \& Shapiro DA First clinical trial of a novel caspase inhibitor: anti-apoptotic caspase inhibitor, IDN-6556, improves liver enzymes. Int J Clin Pharmacol Ther 41, 441-449 (2003). [PubMed: 14703949]

165. Baskin-Bey ES et al. Clinical Trial of the Pan-Caspase Inhibitor, IDN-6556, in Human Liver Preservation Injury. Am J Transplant 7, 218-225, doi:10.1111/j.1600-6143.2006.01595.x (2007). [PubMed: 17227570]

166. Pockros PJ et al. Oral IDN-6556, an antiapoptotic caspase inhibitor, may lower aminotransferase activity in patients with chronic hepatitis C. Hepatology 46, 324-329, doi:10.1002/hep.21664 (2007). [PubMed: 17654603]

167. Shiffman ML et al. Clinical trial: the efficacy and safety of oral PF-03491390, a pancaspase inhibitor - a randomized placebo-controlled study in patients with chronic hepatitis C. Aliment Pharmacol Ther 31, 969-978, doi:10.1111/j.1365-2036.2010.04264.x (2010). [PubMed: 20163376]

168. Szabo G \& Petrasek J Inflammasome activation and function in liver disease. Nat Rev Gastroenterol Hepatol 12, 387-400, doi:10.1038/nrgastro.2015.94 (2015). [PubMed: 26055245]

169. Lee FA et al. Randomized Phase II Study of the X-linked Inhibitor of Apoptosis (XIAP) Antisense AEG35156 in Combination With Sorafenib in Patients With Advanced Hepatocellular Carcinoma (HCC). Am J Clin Oncol 39, 609-613, doi:10.1097/COC.0000000000000099 (2016). [PubMed: 24977690]

170. Kopalli SR, Kang TB \& Koppula S Necroptosis inhibitors as therapeutic targets in inflammation mediated disorders - a review of the current literature and patents. Expert Opin Ther Pat 26, 1239-1256, doi:10.1080/13543776.2016.1230201 (2016). [PubMed: 27568917]

171. Li D et al. Natural Product Kongensin A is a Non-Canonical HSP90 Inhibitor that Blocks RIP3dependent Necroptosis. Cell Chem Biol 23, 257-266, doi:10.1016/j.chembiol.2015.08.018 (2016). [PubMed: 27028885]

172. Dai MC et al. Curcumin protects against iron induced neurotoxicity in primary cortical neurons by attenuating necroptosis. Neurosci Lett 536, 41-46, doi:10.1016/j.neulet.2013.01.007 (2013). [PubMed: 23328441]

173. Conrad M, Angeli JP, Vandenabeele P \& Stockwell BR Regulated necrosis: disease relevance and therapeutic opportunities. Nat Rev Drug Discov 15, 348-366, doi:10.1038/nrd.2015.6 (2016). [PubMed: 26775689]

174. Gujral JS, Knight TR, Farhood A, Bajt ML \& Jaeschke H Mode of cell death after acetaminophen overdose in mice: apoptosis or oncotic necrosis? Toxicol Sci 67, 322-328 (2002). [PubMed: 12011492]

175. Masuichi H et al. Significant role of apoptosis in type-1 autoimmune hepatitis. Osaka City Med J 45, 61-79 (1999). [PubMed: 10723202]

176. Fox CK, Furtwaengler A, Nepomuceno RR, Martinez OM \& Krams SM Apoptotic pathways in primary biliary cirrhosis and autoimmune hepatitis. Liver 21, 272-279 (2001). [PubMed: 11454191]

177. Kuo PC et al. Apoptosis and hepatic allograft reperfusion injury. Clin Transplant 12, 219-223 (1998). [PubMed: 9642513]

178. Gautheron J, Vucur M \& Luedde T Necroptosis in Nonalcoholic Steatohepatitis. Cell Mol Gastroenterol Hepatol 1, 264-265, doi:10.1016/j.jcmgh.2015.02.001 (2015). [PubMed: 28210679]

179. Davidson DG \& Eastham WN Acute liver necrosis following overdose of paracetamol. Br Med J 2, 497-499 (1966). [PubMed: 5913083]

180. Tzimas GN et al. Correlation of cell necrosis and tissue calcification with ischemia/reperfusion injury after liver transplantation. Transplant Proc 36, 1766-1768, doi:10.1016/j.transproceed. 2004.06.013 (2004). [PubMed: 15350473]

181. Jaeschke H, Cover C \& Bajt ML Role of caspases in acetaminophen-induced liver injury. Life Sci 78, 1670-1676, doi:10.1016/j.lfs.2005.07.003 (2006). [PubMed: 16226279]

182. Anstee QM et al. Impact of pan-caspase inhibition in animal models of established steatosis and non-alcoholic steatohepatitis. J Hepatol 53, 542-550, doi:10.1016/j.jhep.2010.03.016 (2010). [PubMed: 20557969] 


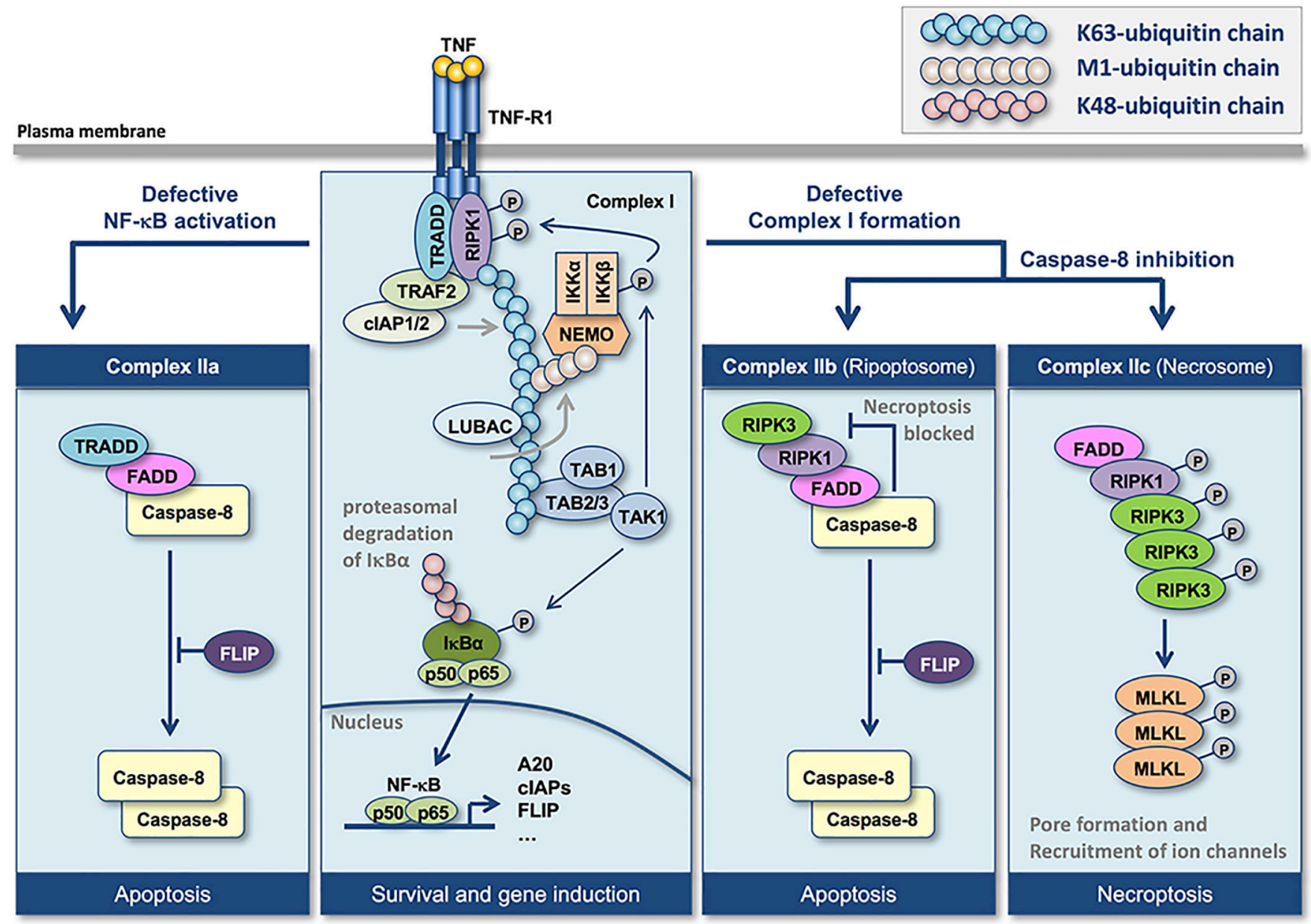

Figure 1. Mediators of TNF-dependent programmed cell death (simplified scheme). Activation of distinct cell death pathways in response to TNF signalling is regulated by diverse post-transcriptional modification steps, including phosphorylation and ubiquitylation. Upon ligation of TNF to its receptor, TNF receptor 1 (TNFR1), distinct signalling complexes can be formed, which is mainly orchestrated through ubiquitylation events that influence cell fate towards survival or cell death. The first complex that forms upon TNF stimulation is complex I, consisting of the adaptor protein TNFRSF1A-associated via death domain (TRADD), receptor-interacting serine/threonine-protein kinase 1 (RIPK1) and the E3 ligases TNF receptor-associated factor 2 (TRAF2), cellular inhibitor of apoptosis 1 (CIAP1) and CIAP2, which together mediate the main ubiquitylation events (for example, ubiquitylation of K63 and K48), thereby enabling the further recruitment of the linear ubiquitin chain assembly complex (LUBAC), the inhibitor of NF- $\kappa B$ (I $\kappa B$ ) kinase (IKK) complex (comprising IKK subunit- $\alpha$ (IKKa), IKK $\beta$ and NF- $\kappa B$ essential modulator (NEMO)), orphan nuclear receptor TAK1 and its adaptor proteins (TAK1-binding protein 1 (TAB1), TAB2 and TAB3) and subsequent activation of the pro-survival transcription factor nuclear factor- $\kappa \mathrm{B}(\mathrm{NF}-\kappa \mathrm{B})$. Upon genetic or pharmacological inactivation of NF- $\kappa \mathrm{B}$ or other factors that drive NF- $\mathrm{kB}$ activation (such as TAK1 or NEMO), deubiquitylation and release of RIPK1 from complex I can promote the formation of other complexes that tip the balance of TNF signalling towards cell death. Complexes containing FAS-associated death 
domain protein (FADD), caspase 8 and RIPK1 (complex IIb) or alternatively TRADD (complex IIa) typically trigger apoptosis. By contrast, complexes containing RIPK1 and RIPK3 (complex IIc) typically activate necroptosis, a form of programmed necrosis, via RIPK3-mediated phosphorylation of mixed lineage kinase domain-like protein (MLKL). Complex formation is further modified by deubiquitinases such as zinc-finger protein A20, ubiquitin carboxyl-terminal hydrolase CYLD or ubiquitin carboxyl-terminalhydrolase 2. cFLIP, cellular FLICE-like inhibitory protein; p50, nuclea rfactor NF- $\mathrm{kB}$ subunit p50; p65, nuclear factor NF- $\kappa B$ subunit $\mathrm{p} 65$. 


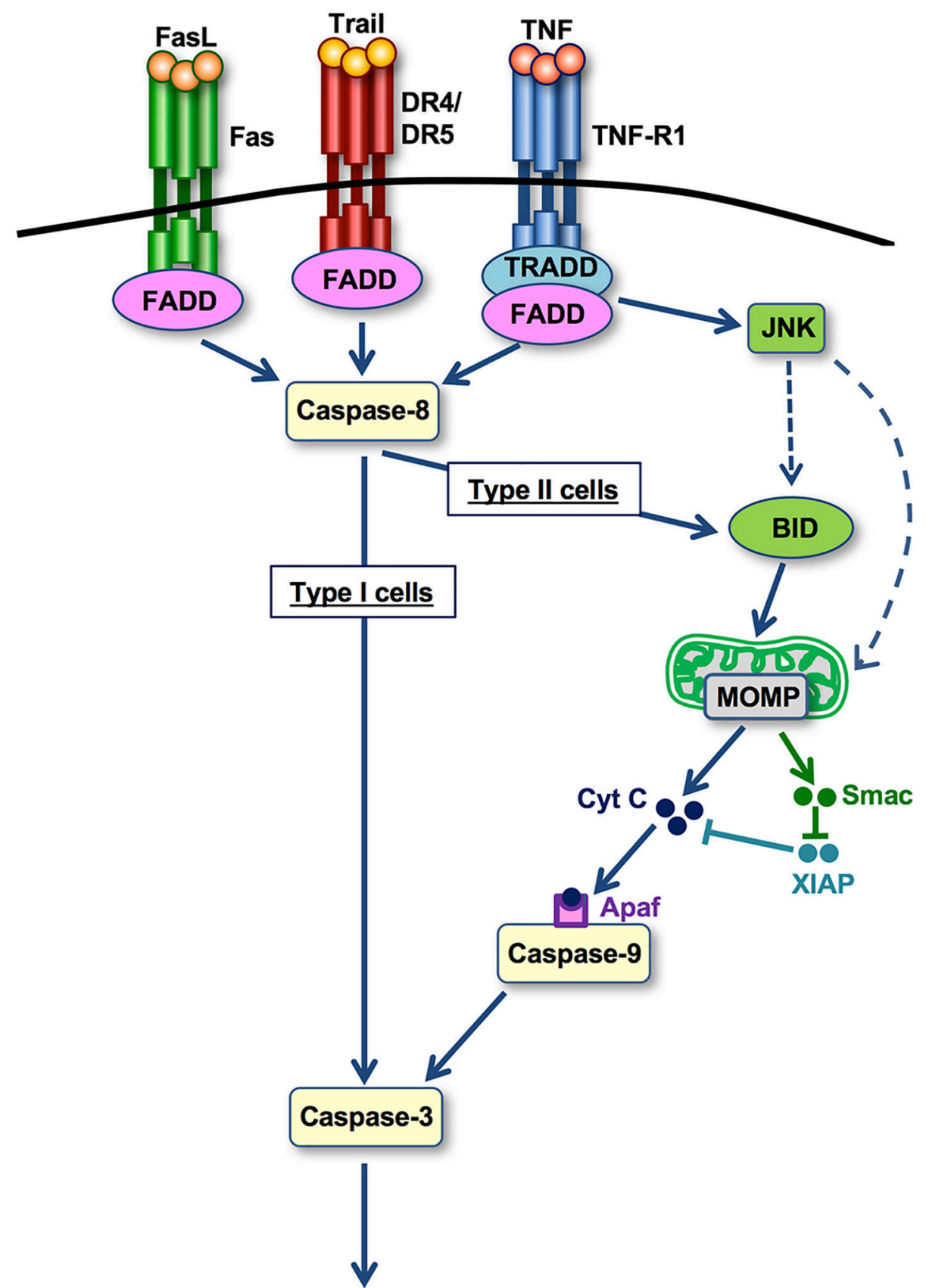

\section{Apoptosis}

Figure 2. Mechanisms of death receptor-induced apoptosis.

Following activation of apoptosis-mediating surface antigen FAS, TNF-related apoptosisinducing ligand (TRAIL) receptors death receptor 4 (DR4; also known as TNFRSF10A) or DR5 (also known as TNFRSF10B) or TNF receptor 1 (TNFR1), caspase 8 becomes activated (Fig. 1). In type I cells (which induce apoptosis independent of mitochondria), caspase 8 activation is sufficient to trigger caspase 3 activation and apoptosis. In type II cells (in which apoptosis is mitochondria-dependent), caspase 8 cleaves BH3-interacting domain death agonist (BID), thereby triggering mitochondrial outer membrane permeabilization 
(MOMP) and release of cytochrome $\mathrm{c}$ and second mitochondria-derived activator of caspase (SMAC). SMAC neutralizes E3ubiquitin-protein ligase XIAP, thereby allowing the cytochrome c-apoptotic protease-activating factor 1 (APAF1) complex to trigger caspase 9 activation, which in turn triggers activation of caspase 8. JUN N-terminal kinase (JNK) activation amplifies this mitochondrial amplification pathway (dashed line) in TNFR1induced apoptosis. FADD, FAS-associated death domain protein; FASL, FAS antigen ligand; TRADD, TNFRSF1A-associated via death domain. 


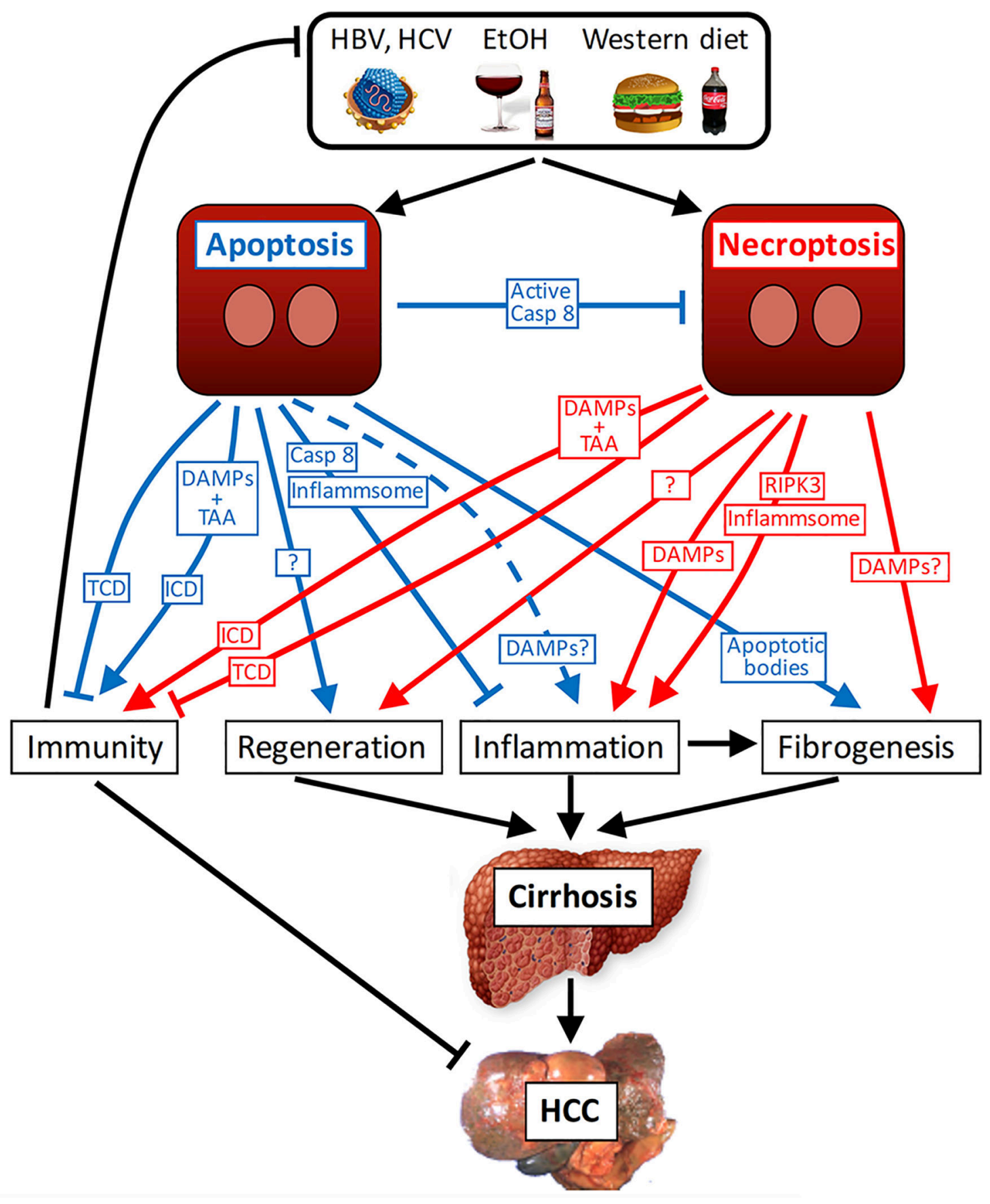

Figure 3. Apoptosis and necroptosis and the development of liver cirrhosis and HCC.

Apoptosis and necroptosis, triggered by chronic liver diseases such as viral hepatitis, nonalcoholic steatohepatitis and alcoholic steatohepatitis, can trigger hepatic regeneration, inflammation and fibrogenesis. Apoptosis is considered a less reactive form of cell death than necroptosis, which is explained by the rapid phagocytosis of apoptotic cells and the caspase 8-mediated inhibition of the NACHT, LRR and PYD domains-containing protein 3 (NLRP3) inflammasome. However, it seems that apoptotic cells can nonetheless release selective DAMPs or low levels of DAMPs and thereby also trigger inflammation in specific 
settings (dashed line). Necroptosis on the other hand not only results in increased cellular leakage and damage-associated molecular pattern (DAMP) release but also can contribute to inflammation via receptor-interacting serine/threonine-protein kinase 3 (RIPK3)-mediated NLRP3 inflammasome activation. Chronic regeneration, inflammation and fibrogenesis contribute to progression to cirrhosis and hepatocellular carcinoma (HCC). In specific settings, apoptosis and necroptosis can trigger immunogenic cell death (ICD). ICD requires simultaneous release of DAMPs and antigens or tumour-associated antigens (TAAs) in sufficient amounts and probably inhibits HCC development and might also contribute to antiviral immunity. In the absence of sufficient DAMP and TAA release, tolerogenic cell death (TCD) can occur. 


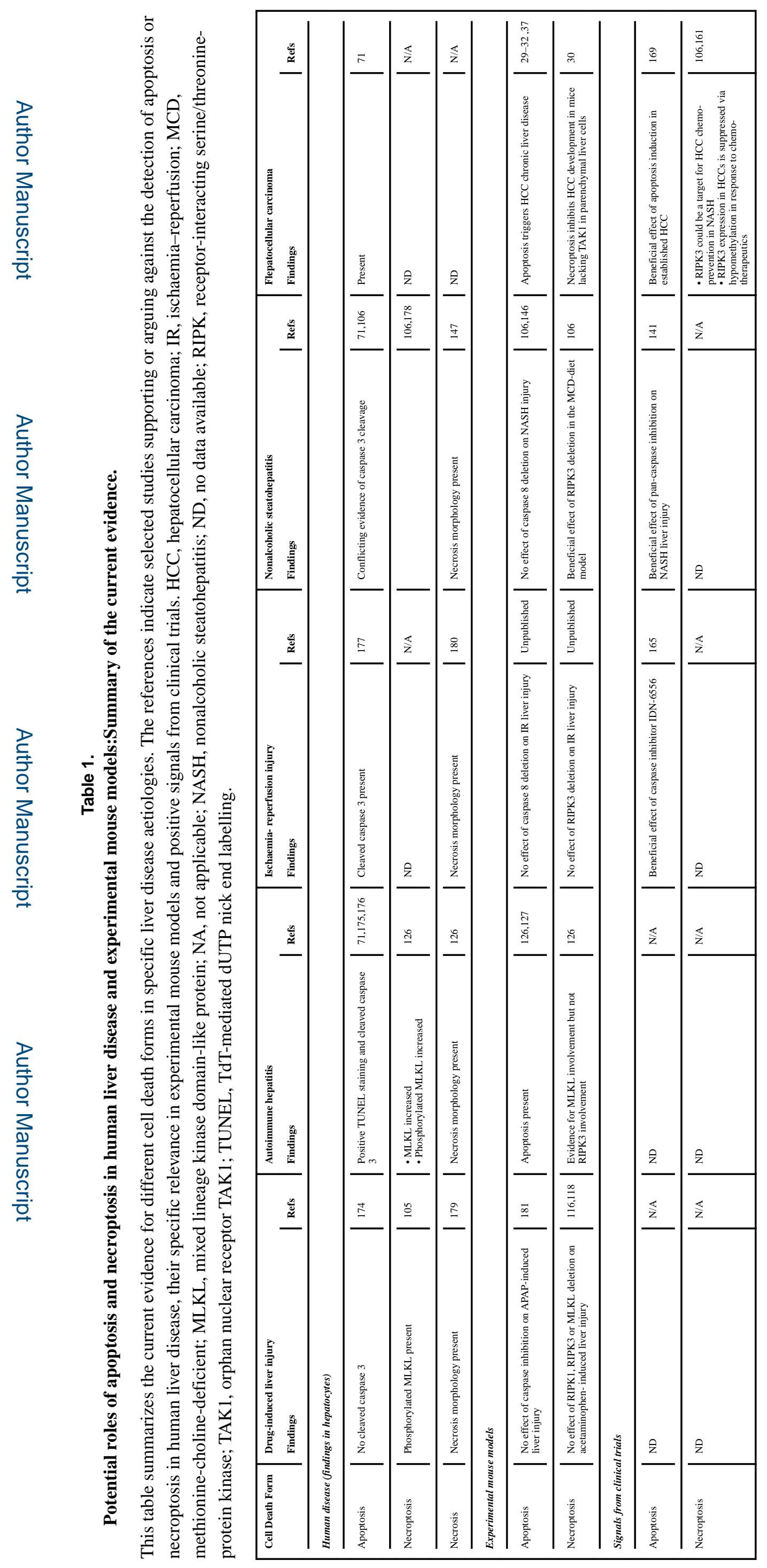

